\title{
Chemical Bonding and Structural Information of Black Carbon Reference Materials and Individual Carbonaceous Atmospheric Aerosols
}

\author{
Rebecca J. Hopkins ${ }^{\dagger}$, Alexei V. Tivanski ${ }^{\dagger}$, Bryan D. Marten ${ }^{\ddagger}$ and Mary K. Gilles ${ }^{*}{ }^{\dagger}$ \\ $\dagger^{*}$ Chemical Sciences Division, Lawrence Berkeley National Laboratory, 1 Cyclotron Road, \\ Berkeley, CA 94720, USA. \\ Lowell High School, 1101 Eucalyptus Drive, San Francisco, CA 94132, USA.
}

*Corresponding author: Mary K. Gilles email MKGilles@lbl.gov

\begin{abstract}
The carbon-to-oxygen ratios and graphitic nature of a range of black carbon standard reference materials (BC SRMs), high molecular mass humic-like substances (HULIS) and atmospheric particles are examined using scanning transmission X-ray microscopy (STXM) coupled with near edge X-ray absorption fine structure (NEXAFS) spectroscopy. Using STXM/NEXAFS, individual particles with diameter $>100 \mathrm{~nm}$ are studied, thus the diversity of atmospheric particles collected during a variety of field missions is assessed. Applying a semi-quantitative peak fitting method to the NEXAFS spectra enables a comparison of BC SRMs and HULIS to particles originating from anthropogenic combustion and biomass burns, thus allowing determination of the suitability of these materials for representing atmospheric particles. Anthropogenic combustion and biomass burn particles can be distinguished from one another using both chemical bonding and structural ordering information. While anthropogenic combustion particles are characterized by a high proportion of aromatic-C, the presence of benzoquinone and are highly structurally ordered, biomass burn particles exhibit lower structural ordering, a smaller proportion of aromatic-C and contain a much higher proportion of oxygenated functional groups.
\end{abstract}

Key Words: Aerosol, black carbon, NEXAFS, HULIS, biomass burn, soot. 


\section{Introduction}

Carbonaceous aerosols are emitted into Earth's atmosphere from natural and anthropogenic sources, which include biomass burning, natural fires and the combustion of coals, diesel and jet fuels. Aerosols that contain "black carbon" (BC), commonly referred to as soot and identified as a lightabsorbing component of aerosols, play an important role in influencing the radiative properties of Earth's atmosphere, through both direct and indirect effects. The direct effect describes the scattering and absorption of solar radiation by aerosol particles. The indirect effect describes the contribution particles make to the radiation budget when they act as cloud condensation nuclei $(\mathrm{CCN})$ and become activated to form cloud droplets in supersaturated water vapor. This process increases the surface area of aqueous aerosol that can reflect radiation away from Earth's surface. The direct and indirect effects lead to a warming and cooling of the atmosphere, respectively. The interplay of these two effects is a topic of debate. While some researchers calculate a positive forcing from BC [Chung and Seinfeld, 2005; Jacobson, 2004], the overall effect of increasing aerosol concentration in the atmosphere remains unclear [Jones, et al., 2005]. The uncertain role of BC in global climate change is due to the strong dependence of radiative forcing on its chemical and physical properties. Wide variations in these properties are observed, including the mixing state of BC [Jacobson, 2001] and its distribution and residence time in the atmosphere.

Newly generated carbonaceous particles are initially hydrophobic, but reaction with atmospheric gaseous species such as $\mathrm{NO}_{2}, \mathrm{SO}_{2}, \mathrm{HNO}_{3}$ and $\mathrm{H}_{2} \mathrm{SO}_{4}$ transforms their surfaces into hydrophilic reaction sites that can readily absorb water. This in turn affects cloud formation rates [Chughtai, et al., 1996; Chughtai, et al., 1999a; Chughtai, et al., 1999b; Rogaski, et al., 1997]. Uptake of water depends on the chemical properties of the surface. Surface properties vary as a function of combustion conditions, fuel composition and surface oxidation of BC in air. More efficient combustion regimes lead to greater abundances of oxygen and defective structures at the particles interface, promoting higher chemical reactivity [Chughtai, et al., 2002; Su, et al., 2004]. An important step in quantifying the magnitude of the indirect effect is to measure the uptake coefficient of water onto BC particles $\left(\gamma_{\mathrm{BC}}\right)[$ Chughtai, et al., 1996; Chughtai, et al., 1999a; Chughtai, et al., 1999b; Rogaski, et al., 1997; Wyslouzil, et al., 1994]. Determining the variability of $\gamma_{\mathrm{BC}}$ requires understanding the fundamental differences between $\mathrm{BC}$ reference materials used in the laboratory and BC particles in the atmosphere. The process of atmospheric aging should also be considered, as it will lead to a variation of atmospheric BC. 
The term BC is used to describe the light-absorbing component of submicron aerosol, typically measured at a single wavelength $(550 \mathrm{~nm})$. This has generally been attributed to soot, which is known from Raman spectroscopy to have a graphitic-like structure [Mertes, et al., 2004; Rosen and Novakov, 1977]. Soot cannot be considered as pure graphite, as it contains species other than elemental carbon and displays different electronic properties and structure [Andreae and Gelencser, 2006; Bond and Bergstrom, 2006]. A recent publication noted that certain organic compounds may contribute to light absorption in atmospheric aerosol, prompting a review of this definition of BC [Andreae and Gelencser, 2006]. Laboratory measurements and field studies indicate that a variety of carbonaceous atmospheric aerosol absorb light over a large spectral range [Havers, et al., 1998; Hoffer, et al., 2006; Mukai and Ambe, 1986]. In addition to BC that strongly absorbs $550 \mathrm{~nm}$ light, some organic aerosols can efficiently absorb light in the near UV region of the spectrum. This organic material, tentatively termed "brown carbon" due to its yellowish/brown appearance, is likened to natural humic or fulvic acids, more generally termed as high molecular mass humic-like substances (HULIS) [Havers, et al., 1998; Kiss, et al., 2001; Krivacsy, et al., 2001; Krivacsy, et al., 2000; Zappoli, et al., 1999]. HULIS found in atmospheric aerosol is thought to originate directly from biomass burning or decomposition, in addition to heterogeneous reactions from dienes in the presence of sulfuric acid [Andreae and Gelencser, 2006; Limbeck, et al., 2003].

Various soot surrogates are employed in the laboratory as atmospheric BC mimics. These surrogates can be assigned to several classes as determined by their elemental composition, particle size and morphology. Soot produced from hydrocarbon combustion is one class of materials studied here. Particles generated in diffusion flames (ethylene, methane and $n$-hexane) and diesel exhaust soot are examined. $n$-hexane soot is composed of between $87-95 \%$ carbon and contains a variety of oxygen containing functional groups, including alkyl ketones, aryl ethers, anhydrides and substituted aromatic groups [Akhter, et al., 1985]. The International Steering Committee for Black Carbon Reference Materials (ISCBCRM) recommends $n$-hexane soot as a suitable standard to represent atmospheric BC, due to chemical and physical similarities and because of the significant characterization and reactivity data in the literature [Akhter, et al., 1985; Chughtai, et al., 2002; Chughtai, et al., 1999a; Chughtai, et al., 1999b; Goldberg, 1985; Masiello and Schmidt, 1999]. Graphites represent the second class of soot surrogates studied. This work considers two graphitic materials; carbon soot from resistively heated graphite and micronized graphite. Highly oriented pyrolytic graphite is highly absorbing and inert under atmospheric conditions [Bond and Bergstrom, 2006]. It is essentially a highly ordered periodic stack of graphene sheets comprised of a hexagonal lattice of carbon with strong $\mathrm{sp}^{2}$ bonding, thus representing 
$100 \% \mathrm{sp}^{2}$ hybridization. Highly oriented pyrolytic graphite is used here for comparison purposes, not as a potential laboratory surrogate. The final class of materials can be described as having an amorphous structure. Two types of materials studied in this paper are amorphous carbon and Palas soot. Amorphous carbon has a mixture of $\mathrm{sp}^{2}$ and $\mathrm{sp}^{3}$ bonds and displays no long-range order. Palas soot is generated by spark discharge between graphitic electrodes and also has a disordered structure [Wentzel, et al., 2003].

Characterization of light absorbing atmospheric particles, their variation, and identification of suitable reference materials to serve as laboratory surrogates is the subject of this work. The approach is to study a variety of laboratory generated and commercially available soot samples and HULIS using scanning transmission X-ray microscopy (STXM) with near-edge X-ray absorption fine structure (NEXAFS) spectroscopy at the carbon (C) and oxygen (O) K-edges and compare these to atmospheric particles collected during various field campaigns. While this method highlights differences in chemical functional groups and structural ordering, it does not provide any information on the optical properties of these materials. This would be an additional verification of the suitability of a given soot standard.

STXM/NEXAFS is a novel synchrotron based technique that enables X-ray absorption spectra to be recorded from single particles with diameters $>100 \mathrm{~nm}$, while simultaneously recording images with high spatial resolution $(\sim 35 \mathrm{~nm})$. The higher spatial resolution of high resolution transmission electron microscopy $(\sim 0.2 \mathrm{~nm})$ and scanning electron microscopy $(\sim 10 \mathrm{~nm})$ can provide more detailed information on particle morphology [Laskin, et al., 2006; Posfai, et al., 2004]. However, STXM/NEXAFS can spatially map differences in local chemical bonding, enabling chemical heterogeneity to be determined. This offers advantages over techniques previously used to study chemical bonding in atmospheric particles that examine bulk samples [Mertes, et al., 2004; Sze, et al., 2001]. An extensive guide to NEXAFS spectroscopy is in existence [Stöhr, 2003] and also a review of NEXAFS spectroscopy related to environmental studies [Myneni, 2002], in addition to the application of the technique to carbonaceous particulate matter [Braun, et al., 2004; di Stasio and Braun, 2006] and atmospheric particles [Maria, et al., 2004; Russell, et al., 2002], thus only a brief outline of the technique is presented here. In NEXAFS spectroscopy, X-rays incident upon a sample are absorbed through excitations of core electrons into an unoccupied molecular orbital, resulting in considerable fine structure above the absorption edge. NEXAFS is element specific as the X-ray absorption edges of different elements occur at different energies. Furthermore, NEXAFS spectra display sensitivity to the local bonding environment of the absorbing atom and can be considered fingerprints of particular carbonaceous compounds. Information on a samples structural ordering is obtained from exciton peaks 
in the NEXAFS spectrum and by calculating the degree of $\mathrm{sp}^{2}$ hybridization. NEXAFS spectroscopy is therefore a highly suitable technique for studying the similarities and differences of a variety of BC reference materials and atmospheric particles.

\section{The Experimental Technique}

STXM studies were performed on solid carbonaceous samples at the Advanced Light Source (ALS) Berkeley, CA. Soot samples studied include resistively heated graphite, micronized graphite, soot produced from ethylene, methane and $n$-hexane diffusion flames, diesel exhaust soot, Palas soot and amorphous carbon. Resistively heated graphite and amorphous carbon were purchased from Sigma Aldrich. Ethylene soot was obtained from an ethylene/air diffusion flame produced with ethylene and air flow rates of $3.7-4.3 \mathrm{~cm}^{3} \mathrm{~s}^{-1}$ and $458 \mathrm{~cm}^{3} \mathrm{~s}^{-1}$, respectively [Michelson, et al., 2007]. Methane and air flow rates of $12.8 \mathrm{~cm}^{3} \mathrm{~s}^{-1}$ and $233 \mathrm{~cm}^{3} \mathrm{~s}^{-1}$, respectively, were used to produce methane soot from an inverted methane/air diffusion flame. $n$-hexane soot, produced from a diffusion flame under quiescent conditions was supplied by ISCBCRM. The diesel soot NEXAFS spectrum was supplied by A. Braun [Braun, et al., 2004; di Stasio and Braun, 2006] and was acquired from NIST SRM 1650 purchased from NIST in Gaithersburg, MD, USA [Huggins, et al., 2000]. HULIS samples, including Suwannee River Fulvic acid 1S101F, Suwannee River humic acid 2S101H and Suwannee River aquatic NOM $1 \mathrm{R} 101 \mathrm{~N}$ were purchased from the international humic substances society, MN, USA. Atmospheric samples include NIST SRM 1649a, an urban dust purchased from NIST [Currie, et al., 2002]. In addition, particles were collected during various field campaigns, namely the Megacity Initiative: Local and Global Research Observations (MILAGRO), Aerosol Characterization Experiment (ACE-Asia) and biomass burns sampled in Yosemite National Park, CA and Flagstaff, AZ.

Thin coatings of surrogate soot and NIST SRM 1650 samples were deposited onto $\mathrm{Si}_{3} \mathrm{~N}_{4}$ windows to avoid total absorption of the X-ray beam, enabling a transmission signal to be recorded. This was achieved by applying gentle contact between the crushed powder sample and the $\mathrm{Si}_{3} \mathrm{~N}_{4}$ window and subsequently removing any loose, excess sample. Atmospheric samples were collected directly onto holey carbon coated TEM grids and $\mathrm{Si}_{3} \mathrm{~N}_{4}$ windows using either a Time-Resolved Aerosol Collector (TRAC) [Laskin, et al., 2003] or by direct impaction from an aerosol inlet [Russell, et al., 2002]. Two samples, methane flame and biomass burn particles collected in Flagstaff, AZ, were collected onto quartz filters. 
Substrates containing the particulate matter were transferred to the STXM chamber. The chamber was flushed with helium and maintained at atmospheric pressure, minimizing the loss of volatile or semi-volatile organic components from the samples. Particles with sufficient optical thickness to allow transmission of the X-ray beam were chosen for study and NEXAFS spectra were acquired over the $\mathrm{C}(280-320 \mathrm{eV})$ and $\mathrm{O}(525-555 \mathrm{eV}) \mathrm{K}$-edges. Locating regions of the sample with an appropriate optical thickness was often difficult. NEXAFS spectra of BC SRMs were averaged over either a region with agglomerated particles or multiple small particles. The Palas soot spectrum was obtained from 13 distinct particles with diameter $\leq 450 \mathrm{~nm}$; ethylene flame soot was measured more than 20 times [Michelson, et al., 2007]; the $n$-hexane spectrum was obtained from the edge portions $(0.4 \mu \mathrm{m} \times 0.6 \mu \mathrm{m})$ of a large agglomerate; the methane flame soot, amorphous carbon, micronised graphite and resistively heated graphite spectra were averaged over a region $(\sim 0.3 \mu \mathrm{m} \times 0.3 \mu \mathrm{m})$. To ensure a linear regime for the spectra, only regions with OD $<1.2$ were included in the averaging process. Averaging over several particles or multiple regions of agglomerates minimizes uncertainty arising from variations between particles. Since the agglomerates or multiple particles would have varying orientations with respect to the incident radiation, this also eliminates polarization effects. The ACE-Asia, MILAGRO and NIST urban dust 1649 a spectra were obtained by averaging over an entire particle, typically $\geq 1 \mu \mathrm{m}$ in diameter. Over 120 tar ball particles with diameter in the range $150-500 \mathrm{~nm}$ were measured from the Yosemite sample. These tar balls display a characteristic NEXAFS spectrum [Tivanski, et al., submitted]. The Flagstaff, AZ, biomass burn spectrum was recorded from a single particle $\sim 2 \mu \mathrm{m}$ diameter due to the sparse loading of this sample.

Two STXM instruments are operational at the ALS and they are located at beamlines 5.3.2 and 11.0.2. Beamline 5.3.2 is a bending magnet beamline that produces horizontally polarized radiation. It uses a spherical grating monochromator to tune the X-ray energy over the range $250-600 \mathrm{eV}$ [Warwick, et al., 2002]. This monochromator is optimized at the $\mathrm{C} 1 \mathrm{~s}$ absorption edge, providing an energy resolution of $100 \mathrm{meV}$. Beamline 11.0.2 is an undulator beamline operating with a plane grating monochromator, with two gratings ruled with 150 and 1200 grooves $\mathrm{mm}^{-1}$. The polarization of this beamline can be varied, but was typically used in the horizontal orientation. This beamline operates over the energy range $200-1900 \mathrm{eV}$, offering considerably more flux than beamline 5.3.2 due to the undulator insertion device $\left(1 \times 10^{12}-1 \times 10^{13}\right.$ versus $1 \times 10^{7}$ photons $\mathrm{s}^{-1}$ at $\left.1.9 \mathrm{GeV}, 400 \mathrm{~mA}\right)$. However, the zone plate focuses only a small percentage of this light onto the sample. As beamline 11.0.2 provides a higher flux, data acquisition times are typically shorter. The energy scale of the 
NEXAFS spectra were calibrated using known $\mathrm{CO}_{2}$ transitions $(3 \mathrm{~s}(v=0)$ and $3 \mathrm{p}(v=0))[M a$, et al., 1991].

A schematic diagram illustrating the key STXM components is presented in Figure 1. The X-ray beam enters the STXM chamber through a $50 \mathrm{~nm}$ thick $\mathrm{Si}_{3} \mathrm{~N}_{4}$ window, which isolates the instrument from the ultrahigh vacuum of the beamline. A custom made Fresnel zone plate, engineered at the Centre for X-Ray Optics, Lawrence Berkeley National Laboratory, focuses the X-ray beam to a diffraction limited spot size, typically $35 \mathrm{~nm}$ for these experiments. The beam stop at the centre of the zone plate prevents unfocused radiation from reaching the sample and an order selective aperture eliminates higher order diffracted light, permitting only the first order diffracted light to reach the sample. The STXM runs in multiple modes allowing images, spectra and stacks to be recorded. The intensity of X-rays transmitted through the sample at a fixed energy is measured as the sample is raster scanned to record an image. Transmission spectra are collected by varying the monochromator energy at a fixed sample position. Sequences of images are acquired at closely spaced energies to record a stack of images. A stack is essentially a three dimensional map in position, energy and transmission. NEXAFS spectra from individual pixels or particular regions of interest on the sample image are extracted from the stack, enabling spatial mapping of chemical bonding information [Hitchcock, et al., 2001]. This technique is operated in the transmission mode in this work; therefore the resultant signal is recorded from an entire particle representing an average of both surface and bulk properties.

The transmitted signal is converted to optical density (OD) and is dependent upon sample thickness, density and composition as described below:

$$
O D=-\ln \frac{I}{I_{0}}=\mu \rho d
$$

where $I_{0}$ is the incident photon flux intensity, $d$ is the sample thickness, $\mu$ is the mass absorption coefficient and $\rho$ is the density of the sample material. $I_{0}$ is determined by selecting a sample free region of the substrate. All spectra recorded in this study are scaled to a thickness of $100 \mathrm{~nm}$ and density of $1.8 \mathrm{~g} \mathrm{~cm}^{-3}$ using carbon mass absorption coefficients calculated from data supplied by the Centre for X-Ray Optics. This scaling process essentially normalizes the spectra to the same total carbon content, thus allowing a meaningful comparison of the samples studied. 


\section{Results and Discussion}

A visual comparison of NEXAFS spectra recorded from BC SRMs, HULIS and atmospheric particulate samples provides an initial, qualitative assessment of similarities and differences between these species. A semi-quantitative peak fitting method provides a more exacting comparison of the spectra. This method determines the percentage contribution that each functional group makes to the total carbon in the sample. This information in combination with the ratio of carbon-to-oxygen $(\mathrm{C} / \mathrm{O})$ present in the materials, quantifies the degree of oxygenation. Analysis of this body of information enables an assessment of suitable BC SRMs and HULIS for representing black carbon and biomass burn particles in the laboratory.

\subsection{Classifying Surrogate Soot Standards and Atmospheric Particles using NEXAFS Spectroscopy}

Images of $\mathrm{BC}$ particles collected during the MILAGRO field campaign are illustrated in Figure 2. These images, shown on the same scale, were recorded at; the pre-edge $(280 \mathrm{eV}), 1 \mathrm{~s}-\pi^{*}$ aromatic $\mathrm{C}=\mathrm{C}$ peak $(285.3 \mathrm{eV}), 1 \mathrm{~s}-\sigma^{*}$ aromatic $\mathrm{C}=\mathrm{C}$ peak $(292 \mathrm{eV})$ and the post-edge $(320 \mathrm{eV})$. The pre-edge absorbance is due to the weak but finite absorption of other molecular species present in the sample and this is measured at 280 and $525 \mathrm{eV}$ for $\mathrm{C}$ and $\mathrm{O}$-edges, respectively. The particle is not visible in the 280 $\mathrm{eV}$ image (see Figure 2 (a)), suggesting the presence of either a very small amount or no molecular species other than carbon. The post-edge absorbance corresponds to the number of atoms at a particular edge and is measured at 320 and $550 \mathrm{eV}$ for $\mathrm{C}$ and O-edges, respectively. The image recorded at $320 \mathrm{eV}$ (see Figure 2 (d)) has considerably higher contrast relative to the image background. This contrast is greater than for the image recorded at $280 \mathrm{eV}$, illustrating high carbon content in the particle. The difference between the post-edge and pre-edge absorbencies represents the total amount of a particular element in a sample. Figures 2 (b) and (c) are recorded at energies corresponding to the $1 \mathrm{~s}-\pi^{*}$ aromatic $\mathrm{C}=\mathrm{C}$ and $1 \mathrm{~s}-\sigma^{*}$ aromatic $\mathrm{C}=\mathrm{C}$ transitions, respectively. The particle in both of these images shows higher contrast relative to the image recorded at $280 \mathrm{eV}$, indicating the presence of these transitions in this particle.

Figure 3 presents NEXAFS spectra from a myriad of BC SRMs, all normalized to the same total carbon content. The spectra are from highly oriented pyrolytic graphite (this spectrum is from ref [Lenardi, et al., 2005]), two treated graphites (resistively heated graphite and micronized graphite), soot generated from $n$-hexane, methane and ethylene flames, diesel exhaust soot (this spectrum is from ref $[d i$ 
Stasio and Braun, 2006]), Palas soot and amorphous carbon. The differing graphitic nature of these soot samples is dependent upon the conditions of the combustion process in which they were formed. The general process is believed to result from polycyclic aromatic hydrocarbons (PAHs) undergoing nucleation to produce soot nuclei [Richter and Howard, 2000], which then grow in mass due to addition of gas-phase species and small PAHs. Another potential mechanism involves reactive coagulation via particle-particle collisions. Amorphous polyaromatic carbon is then believed to undergo dehydrogenation, resulting in ring condensation and fusion leading to partial micro structural ordering and progressively higher degrees of graphitization. The spectrum of highly oriented pyrolytic graphite recorded at the magic angle is use to calculate the $\mathrm{sp}^{2}$ content of BC SRMs using a method outlined below [Lenardi, et al., 2005].

The graphitic nature of the samples is assessed by calculating their $\% \mathrm{sp}^{2}$ hybridization. This quantity is determined by normalizing the area of the $1 \mathrm{~s}-\pi^{*}{ }_{\mathrm{C}=\mathrm{C}}$ peak at $285.3 \mathrm{eV}\left(A_{C=C}^{\text {sample }}\right)$ with the area of the spectrum over the energy range $280-310 \mathrm{eV}\left(A_{280-310}^{\text {sample }}\right)$ for the sample of interest. This ratio is compared with the ratio obtained by normalizing the area of the $1 \mathrm{~s}-\pi^{*}{ }_{\mathrm{C}=\mathrm{C}}$ peak at $285.3 \mathrm{eV}\left(A_{C=C}^{H O P G}\right)$ with the area of the spectrum in the energy range $280-310 \mathrm{eV}\left(A_{280-310}^{H O P G}\right)$ for highly oriented pyrolytic graphite, which is a $100 \% \mathrm{sp}^{2}$ reference sample [Berger, et al., 1988; Lenardi, et al., 1999]. This calculation is performed using the following expression:

$$
\% s p^{2}=\left(\frac{A_{C=C}^{\text {sample }}}{A_{280-310}^{\text {sample }}} \times \frac{A_{280-310}^{H O P G}}{A_{C=C}^{H O P G}}\right) \cdot 100
$$

The calculated $\% \mathrm{sp}^{2}$ hybridization values are presented in Table 1. The spectra shown in Figure 3 are ordered by their graphitic content; highly ordered pyrolytic graphite (top) has the highest amount $(100 \%)$ and amorphous carbon (bottom) has the least (41\%). We note the appearance of a peak at 292 $\mathrm{eV}$ for both BC SRMs and some anthropogenic combustion particles (see Figure 4). In these cases, this peak is thought to arise from the $1 \mathrm{~s}-\sigma^{*} \mathrm{C}=\mathrm{C}$ transition and could indicate a graphitic nature [di Stasio and Braun, 2006]. However, transitions from other functional groups can also occur at this energy.

Spectral contours and $\mathrm{sp}^{2}$ content are used to further categorize the BC SRM spectra, as represented in Figure 3 by different grey shades and line styles. The samples are grouped into four categories for an initial qualitative assessment based on characteristic spectral features; (1) resistively 
heated graphite and micronized graphite, (2) $n$-hexane, methane, ethylene and diesel exhaust soot, (3) Palas soot and (4) amorphous carbon. The highly oriented pyrolytic graphite spectrum displays two pronounced peaks arising from $1 \mathrm{~s}-\pi^{*}$ and $1 \mathrm{~s}-\sigma^{*} \mathrm{C}=\mathrm{C}$ bonds at 285.3 and $292 \mathrm{eV}$, respectively. In addition, a sharp exciton peak at $291 \mathrm{eV}$ induced by the long range order present in graphite is observed [Coffman, et al., 1996]. The appearance of an exciton peak and 100\% $\mathrm{sp}^{2}$ bonding are unique features of highly oriented pyrolytic graphite.

Resistively heated graphite and micronized graphite constitute category (1). They exhibit similar spectral contours with well defined peaks at $285.3 \mathrm{eV}$ and poorly separated absorption features from 286 $-290 \mathrm{eV}$. No exciton peak is observed, suggesting either the absence of long range order, or less ordering than is observed for highly oriented pyrolytic graphite. The three flame generated soot samples (category (2)) appear similar, with $\mathrm{sp}^{2}$ hybridization values consistent within $6 \%$. The low intensity of the $286-290 \mathrm{eV}$ energy regions with respect to the 285 and $292 \mathrm{eV}$ peaks is a feature observed for all three of the flame soot spectra. This low intensity region reflects the relatively small contribution from oxygen containing functional groups. The NEXAFS spectrum of diesel exhaust soot resembles the flame soot samples with the exception of the $286-290 \mathrm{eV}$ region, which appears more prominent. A shoulder at $291 \mathrm{eV}$ is evident in the diesel exhaust soot spectrum. This could be an exciton peak, suggesting the presence of some long range order [Sasaki, et al., 1997]. However, the calculated \% $\mathrm{sp}^{2}$ hybridization value for diesel exhaust soot is $56 \%$. This is considerably lower than for highly oriented pyrolytic graphite, suggesting it is a less graphitic carbonaceous material. A decrease in intensity at energies $>292$ $\mathrm{eV}$ distinguishes the flame soot and diesel exhaust spectra from that of resistively heated graphite and micronized graphite, for which increased absorption above this energy is observed. Palas soot (category (3)) has a distinctly different NEXAFS spectrum from the other samples, even though it displays a $\% \mathrm{sp}^{2}$ value of $52 \%$, similar to that of diesel soot. In contrast to the other samples, there is no sharp rise from $290 \mathrm{eV}$ to the $292 \mathrm{eV}$ peak. Also, the $286-290 \mathrm{eV}$ region has stronger intensity than the $285 \mathrm{eV}$ peak. Amorphous carbon (category (4)) has a spectral contour similar to resistively heated graphite and micronized graphite. An increase in intensity at energies $>292 \mathrm{eV}$ is observed. However, amorphous carbon has a $\% \mathrm{sp}^{2}$ value that is $\sim 25 \%$ lower; therefore it is placed in a separate category.

NEXAFS spectra recorded from atmospheric particles originating from anthropogenic combustion and biomass burn sources are illustrated in Figure 4. These spectra are grouped according to field campaign and ordered with the largest graphitic content at the top. These samples are selected to demonstrate the variability in atmospheric particle composition between locations and also at a 
particular location at a given time. Samples include the NIST 1649a SRM, particles collected during the MILAGRO and ACE-Asia field campaigns, 'tar balls' collected in Yosemite National Park, CA [Tivanski, et al., submitted] and a biomass burn event in Flagstaff, AZ.

The NIST 1649a SRM was collected in the Washington, DC area for a 12 month period during 1976-77. This sample is intended to represent atmospheric particulate matter collected from an urban area, but without being representative of the area where it was collected [Currie, et al., 2002]. NIST 1649a SRM is recommended by the ISCBCRM as a representative atmospheric BC sample [Masiello and Schmidt, 1999]. This standard is the subject of an inter-comparison study and contains several species including PAHs, polychlorinated biphenyls, chlorinated pesticides, polychlorinated dibenzo-pdioxins and dibenzofurans, 32 different inorganic constituents and carbonate [Currie, et al., 2002]. Although much work has been performed to characterize the chemical composition of NIST 1649a SRM, no work to date has studied this sample on a single particle basis using NEXAFS spectroscopy.

The spectra labeled as (j), (k) and (l) in Figure 4 are from individual particles present in the same NIST 1649a SRM sample. The spectra display similar features with a distinct $\mathrm{C}=\mathrm{C}$ aromatic peak at $285.3 \mathrm{eV}$, a prominent $286-290 \mathrm{eV}$ region with poorly separated absorption features (attributed to a variety of functional groups) and a rise in absorbance at energies higher than $290 \mathrm{eV}$. The $\% \mathrm{sp}^{2}$ content varies from 29 to $71 \%$. Although the NIST 1649a SRM was mixed thoroughly, heterogeneity of small samples has been identified as an issue [Currie, et al., 2002]. Individual particles are sampled using STXM/NEXAFS, so this technique is very sensitive to inhomogeneities present in the sample. Some similarities between NIST 1649a SRM and the flame and diesel exhaust samples are evident from a visual comparison of the C K-edge NEXAFS spectra.

The MILAGRO field campaign took place in Mexico City during March 2006. The samples studied here were collected in the northern part of the city, approximately $20 \mathrm{~km}$ from the city centre. It is possible that the combustion of gasoline and diesel fuel may influence the sample, in addition to industrial sources. The five MILAGRO spectra presented in Figure 4 were measured from individual particles collected within a time window of 1.5 hours during peak traffic conditions. The recorded spectra are labeled from (e)-(i) in Figure 4. Particles known to originate from biomass burn sources provide a contrast with the urban NIST and MILAGRO particles. During the ACE-Asia campaign, particles were collected on a day when mixed combustion sources influenced the aircraft sampling location (flight RF15) [Maria, et al., 2004]. Highly spherical 'tar balls' generated from forest fires in 
Oregon were sampled during the Yosemite Aerosol Characterization Study (YACS) in summer 2002. These particles are thought to evolve in aging biomass smoke. The mechanism is believed to involve rapid polymerization of $\mathrm{OH}$ radicals present in the atmosphere with phenolic acids generated during the burning of biomass, producing high molecular weight spherical particles [Posfai, et al., 2004]. Tar balls were present during episodes of high particle light scattering coefficients occurring in mid-August (day of year, DOY, 228-229) and they absorb light in the UV and near-IR region of the electromagnetic spectrum, as determined by a dual wavelength aethalometer $(\lambda=370$ and $880 \mathrm{~nm})$ [Hand, et al., 2005]. Additionally, particles collected during a biomass burn event in Flagstaff, AZ are examined.

MILAGRO (i) and (h) display similar spectral contours. They resemble flame and diesel exhaust soot (category (2)) and possibly spectra from categories (1) and (4) as determined by the low intensity $286-290 \mathrm{eV}$ region. However, the $\% \mathrm{sp}^{2}$ values for MILAGRO (i) and (h) are higher than for all of the surrogate soot samples studied, 82 and 76\%, respectively. MILAGRO (g) has a spectral contour intermediate between the flame and diesel exhaust soot with a lower $\% \mathrm{sp}^{2}$ value of $40 \%$. MILAGRO (e) and (f) exhibit further reduced $\% \mathrm{sp}^{2}$ hybridization values of 6 and $10 \%$, respectively and display spectra unlike flame/diesel soot. Application of the MOZART model predicts biomass burn influence on the sampling site during particle collection. The range of spectral contours observed from the MILAGRO campaign could arise due to influence by different combustion sources, including biomass burning. This range could also indicate atmospheric aging, which would affect the degree of oxidation of these particles.

Biomass burn particles exhibit spectra unlike the surrogate soot, NIST 1649a SRM and some of the MILAGRO particles. NEXAFS spectra from biomass burn particles display spectral characteristics similar to the three HULIS studied, namely Suwannee River aquatic NOM 1R101N, Suwannee River humic acid 2S101H and Suwannee River fulvic acid 1S101F (see Figure 5). Both biomass burn particles and HULIS display an aromatic carbon peak at around $285 \mathrm{eV}$. This spectral feature is narrower and less intense compared with the BC SRMs. In addition, well resolved absorption features are present between $286-290 \mathrm{eV}$, whereas this range generally appears congested in the spectra of anthropogenic particles. The $\% \mathrm{sp}^{2}$ values of the biomass burn samples are variable between locations, but generally much lower than those of BC SRMs. The ACE-Asia particles display the highest $\% \mathrm{sp}^{2}$ values of 34 and 41\%. Tar balls and particles from the Flagstaff, AZ biomass burn are calculated as 9 and $5 \% \mathrm{sp}^{2}$ hybridized, respectively, significantly lower than the BC SRMs and some MILAGRO spectra. The \% $\mathrm{sp}^{2}$ values are calculated as 7, 28 and 29\% for Suwannee River aquatic NOM 1R101N, Suwannee River 
humic acid $2 \mathrm{~S} 101 \mathrm{H}$ and Suwannee River fulvic acid 1S101F, respectively. This indicates that these HULIS do not possess a graphite-like structure as observed for the majority of the BC SRMs.

\subsection{Semi-quantitative Comparison of Surrogate Soot Standards and Atmospheric Particles}

NEXAFS spectra recorded from BC SRMs, HULIS and atmospheric particles are deconvoluted into Gaussian peaks, providing a semi-quantitative method for comparing these samples. Spectral fitting is achieved using an arctangent function for the ionization step at $290.3 \mathrm{eV}$ with a FWHM of $1 \mathrm{eV}$ and Gaussian peaks with variable FWHM, representing the main $1 \mathrm{~s}-\pi^{*}$ and $1 \mathrm{~s}-\sigma^{*}$ transitions below $292 \mathrm{eV}$. In addition, two Gaussian functions are employed to simulate $\sigma^{*}$ transitions above the ionization step. The maxima of these peaks are around 292 and $295 \mathrm{eV}$ with $\mathrm{FWHM}$ of $\leq 3.5 \mathrm{eV}$ and $\leq 5 \mathrm{eV}$, respectively. A spectral fitting program optimizes the fit by minimizing the $\chi^{2}$ value. Spectral fitting enables determination of the dominant transitions, some of which are not evident from an initial inspection of the spectral contour. A semi-quantitative analysis is performed for the main transitions below $292 \mathrm{eV}$ by calculating the percentage that each functional group contributes to the total carbon

present in the sample. This is determined by calculating the ratio of the integral of the individual $\pi^{*}$ or $\sigma^{*}$ peaks to the integral of the spectrum over the energy range $280-320 \mathrm{eV}$.

This method is considered semi-quantitative for several reasons. Firstly, an error in the spectral fit due to the overlap of multiple peaks is anticipated, but quantification of this is non-trivial. This is minimized by 1) fitting the spectrum with the fewest number of peaks needed to obtain a good quality fit and 2) fixing peak energies at the peak maxima of prominent spectral features. The quality of the spectral fit is assessed by calculating the deviation of the simulated fit from the actual spectrum. This is determined in all cases to be $<1 \%$. These identical criteria are employed in the fitting process for each spectrum. Although the reported compositions may not be treated as absolute due to the potential error described above, it is assumed reasonable to compare relative compositions. Evidence to support this arises from agreement between the calculated amount of carbon and oxygen present in a number of samples and the proportion of oxygenated functional groups predicted by the semi-quantitative spectral fitting method. An additional uncertainty arises due to ambiguous peak assignments in regions of the $\mathrm{C}$ and O K-edge NEXAFS spectra. Multiple transitions can occur at similar energies, resulting in potential contribution from multiple functional groups to a given peak. However, comparison of transitions occurring in both the $\mathrm{C}$ and $\mathrm{O}$ NEXAFS spectra can sometimes confirm the presence of certain 
functional groups. Where ambiguity in the assignment of peaks arises, all of the potential candidates are provided.

Spectral fits of C K-edge NEXAFS spectra of a surrogate soot (ethylene soot) and biomass burn sample (Flagstaff, AZ) are displayed in Figure 6 for comparison. A number of sharp resonances are identified by the spectral fitting process. The apportionment of the functional groups differs significantly between the two samples. Several resonance transitions are common to both of these spectra, appearing at $285.3,286.7,287.4,288.5$ and $289.5 \mathrm{eV}$. An additional resonance is unique to each of the spectra; ethylene soot exhibits a peak at $284.2 \mathrm{eV}$ and the biomass burn particle displays a distinct peak at 290.5 $\mathrm{eV}$.

The $1 \mathrm{~s}-\pi^{*} \mathrm{C}=\mathrm{C}$ peak at $285.3 \mathrm{eV}$ originates from either protonated/alkylated or carbon substituted aromatic-C and is herein referred to as aromatic-C [Urquhart, et al., 2000]. An asymmetry in this peak is observed in the ethylene soot spectrum. The prominent shoulder is evident at the low energy side of the peak maximum. This shoulder is fit with a peak centered at $284.2 \mathrm{eV}$ and assigned as a resonance transition arising from the aromatic carbon atoms in benzoquinone. This has been observed previously in soot generated from an ethylene flame [di Stasio and Braun, 2006]. The two carbonyl groups attached to the benzene ring in benzoquinone gives rise to an additional resonance at around 286 $\mathrm{eV}$ [di Stasio and Braun, 2006]. This resonance is shifted to higher energy relative to the $284.2 \mathrm{eV}$ peak due to the polarization of the $\mathrm{C}=\mathrm{O}$ bond caused by the electronegativity difference between the carbon and oxygen atoms. The congestion of peaks in the spectral region above $286 \mathrm{eV}$ makes it difficult to determine the contribution of this benzoquinone resonance at $286 \mathrm{eV}$. The peaks at 286.7, 287.4, 289.5 and $290.5 \mathrm{eV}$ could contain contributions from several functional groups, which have overlapping resonances in these regions. However, apart from the peak at $287.4 \mathrm{eV}$, all of the overlapping functional groups are from a type of carbon-oxygen bond. The $1 \mathrm{~s}-\pi^{*}$ resonance at $286.7 \mathrm{eV}$ could be either Osubstituted aromatic carbon, as in the case of phenol or aryl ether (referred to as phenolic-C herein) [Cody, et al., 1995] or a ketone carbonyl group. The peak at $287.4 \mathrm{eV}$ corresponds to a $1 \mathrm{~s}-\sigma^{*}$ transition from aliphatic carbon atoms or a $1 \mathrm{~s}-\pi^{*}$ transition from aromatic carbonyl groups [Cody, et al., 1998] and the $1 \mathrm{~s}-\pi^{*}$ resonance at $288.5 \mathrm{eV}$ is unambiguously assigned as carboxyl carbon [Urquhart, et al., 1999]. The peak at 289.5 arises from transitions taking place for O-substituted alkyl carbon atoms, including alcohol groups [Scheinost, et al., 2001] or carbonyl groups [Urquhart and Ade, 2002]. Finally, at 290.5 $\mathrm{eV}$, the carbon atoms in carbonyl groups (possibly carbonate) show absorption [Urquhart and Ade, 2002], but this transition is only observed in the biomass burn particle spectrum. 
Figure 7 illustrates $\mathrm{O}$ K-edge NEXAFS spectra recorded from ethylene soot and a biomass burn particle collected in Flagstaff, AZ. These spectra are used to support some of the assignments considered above in the C K-edge NEXAFS spectra. Although O K-edge NEXAFS spectra are generally composed of broader resonances than observed at the $\mathrm{C} \mathrm{K}$-edge, it is still possible to extract functional group information. A broad $1 \mathrm{~s}-\sigma^{*}$ transition centered at $\sim 538 \mathrm{eV}$ is common to both the ethylene soot and biomass burn particle spectra. This peak may contain contributions from ketone, alcohol and phenol functional groups. A small, narrower peak attributed to overlapping $1 \mathrm{~s}-\pi^{*}$ resonances is present in both spectra, appearing in the energy range 529.9 - $533.5 \mathrm{eV}$. However, this peak appears broader in the ethylene soot spectrum and the peak maximum is shifted to lower energy. This peak broadening indicates the contribution from multiple functional groups including a $\mathrm{C}=\mathrm{O}$ resonance from benzoquinone at $529.9 \mathrm{eV}$, confirming the assignment made in the corresponding carbon spectrum. Both ketone and carboxyl functional groups give rise to resonances between $531-532 \mathrm{eV}$. The $1 \mathrm{~s}-\pi^{*}$ resonances appearing in both the ethylene soot and biomass burn particle spectra could result from various proportions of both of these functional groups. The shoulder at $534.5 \mathrm{eV}$ that appears more prominent in the ethylene soot spectrum, is assigned to a $1 \mathrm{~s}-\sigma^{*} \mathrm{O}-\mathrm{H}$ transition in phenol [Myneni, 2002]. This supports the assignment of phenol in the carbon spectrum.

A visual inspection of the C K-edge spectra presented in Figure 6 suggests that the ethylene soot spectrum is dominated by the aromatic carbon peak. Smaller fractions of oxygen containing functional groups are present compared to the biomass burn particle spectrum. This observation is supported by calculated $\mathrm{C} / \mathrm{O}$ ratios for both samples (see Table 1). The $\mathrm{C} / \mathrm{O}$ ratios of ethylene soot and biomass burn particle collected in Flagstaff, AZ are calculated as 84/16 and 53/47, respectively. This result supports the assignment of additional oxygen-containing functional groups in the biomass burn particle spectrum. The total amount of carbon and oxygen present in the sample is calculated using the following equation:

$$
\frac{x_{O}}{x_{C}}=\frac{O D_{O} \mu_{C} Z_{C}}{O D_{C} \mu_{O} Z_{O}} d
$$

where $x_{C}$ and $x_{O}$ are the number of carbon and oxygen atoms present, respectively. $Z_{C}$ and $Z_{O}$ are the atomic mass of carbon and oxygen, respectively. $O D_{C}$ and $O D_{O}$ are determined from the difference between the pre-edge and post-edge absorptions in the NEXAFS spectra for carbon and oxygen, respectively. Mass absorption coefficients for atomic carbon $\left(\mu_{C}\right)$ and oxygen $\left(\mu_{O}\right)$ are calculated from 
atomic scattering factors [Henke, et al., 1982]. The difference in mass absorption coefficients for carbon and oxygen are $3.8 \times 10^{4} \mathrm{~cm}^{2} / \mathrm{g}(280-320 \mathrm{eV})$ and $2 \times 10^{4} \mathrm{~cm}^{2} / \mathrm{g}(525-550 \mathrm{eV})$, respectively. The thickness of the materials is assumed to be constant. This method yields $\mathrm{C} / \mathrm{O}$ ratios that agree well with independent measurements presented in the literature. For example, the $\mathrm{C} / \mathrm{O}$ ratio derived calculated here for $n$-hexane is $87 / 13$. This compares well with reported elemental compositions of between $87 \%$ C, $11 \% \mathrm{O}$ and $92.5 \% \mathrm{C}, 6 \% \mathrm{O}$ [Akhter, et al., 1985].

Detailed compositional breakdowns determined from spectral fitting of the C K-edge NEXAFS spectra are displayed in Figures 8. These results are presented in four plots to differentiate between the BC SRMs (Figure 8(a)), anthropogenic combustion atmospheric particles (Figure 8(b)), biomass burn atmospheric particles (Figure 8(c)) and HULIS samples (Figure 8(d)). Figure 8(a) shows that generally, BC SRMs are highly carbonaceous materials with smaller amounts of oxygen containing functional groups than HULIS and biomass burn particles. BC SRMs are distinguished by their high aromatic-C content and the presence of benzoquinone. The relative proportion of functional groups varies between the BC SRMs studied. However, we show that the variation within BC SRMs is less than the variation observed between combustion influenced particles in the atmosphere. The following section uses these differences to characterize these materials, enabling comparison of SRMs with atmospheric samples.

Resistively heated graphite and micronized graphite are less oxidized than the other BC SRMs, as evident by low amounts of the alcohol/O-alkyl-C functional group and supported by a $\mathrm{C} / \mathrm{O}$ ratio of 96/4. This high carbon content may indicate that the $287.4 \mathrm{eV}$ peak results from aliphatic-C, rather than the alternative assignment of aromatic carbonyl. The compositional breakdowns for all three flame soot samples are very similar to one another. These materials are more oxygenated than the graphite samples, as reflected by their lower $\mathrm{C} / \mathrm{O}$ ratios (see Table 1). The flame soot samples are characterized by a higher amount of alcohol/O-alkyl-C and a smaller amount of carboxyl; this apportionment is reversed for diesel soot. Diesel soot contains less oxygen than the flame soot samples, as evident from comparison of their spectral contours (see Figure 3). The energy region between $288.6-290.2 \mathrm{eV}$ where peaks from oxygenated functional groups are located is of lower intensity than for the flame soot samples.

Palas soot displays a spectral breakdown significantly different from the other BC SRMs studied, exhibiting no contribution from benzoquinone and a much larger contribution from phenolic-C/aromatic carbonyl. In addition, a contribution from $\mathrm{C}=\mathrm{O} / \mathrm{CH}_{3}, \mathrm{CH}_{2}, \mathrm{CH}$ arises, which is not observed in the other 
surrogate soot samples. Palas soot is further characterized by the presence of an equal quantity of alcohol/O-alkyl-C and carboxyl functional groups. Amorphous carbon displays a similar composition to resistively heated graphite and micronized graphite, with comparable amounts of aliphatic-C/aromatic carbonyl, carboxyl and alcohol/O-alkyl-C functional groups. However, the phenolic-C/aromatic carbonyl functional group is also observed in amorphous carbon. The $\% \mathrm{sp}^{2}$ value is much lower for amorphous carbon than for either of the graphites, illustrating that amorphous carbon is a more disordered material [Bond and Bergstrom, 2006].

Figure 8(b) presents compositional breakdowns for anthropogenic combustion particles. Atmospheric samples are put into this classification based on their spectral appearance and compositional breakdown. The spectral contours of MILAGRO (i), (h) and (g) and NIST (j)-(l) are similar to the graphites, flame generated soot and amorphous carbon (see Figure 4). Similar spectral features include a dominant aromatic-C peak at around $285 \mathrm{eV}$ and a region of comparatively low intensity in the range $286-290 \mathrm{eV}$, signifying the presence of a small proportion of oxygen containing functional groups. The compositional breakdown of MILAGRO (i) is most like resistively heated graphite and amorphous carbon. This is characterized by the presence of relatively small amounts of oxygen containing functional groups and a higher proportion of aromatic- $\mathrm{C}$ and aliphatic groups. MILAGRO (i) displays a similar C/O ratio to resistively heated graphite (99/1 and 96/4, respectively). However, it contains a higher percentage of aromatic-C than resistively heated graphite, which is reflected by its higher $\% \mathrm{sp}^{2}$ value ( $82 \%$ and $69 \%$, respectively). This data suggests that although MILAGRO (i) has a chemical composition similar to resistively heated graphite, it displays structural ordering intermediate between resistively heated graphite and highly ordered pyrolytic graphite $(100 \%$ $\left.\mathrm{sp}^{2}\right)$.

MILAGRO (h) has a compositional breakdown most similar to the flame generated soot. This is characterized by the presence of a larger amount of alcohol/O-alkyl-C than carboxyl and an intermediate amount of aliphatic/aromatic carbonyl. A small amount of phenolic-C/ketone $\mathrm{C}=\mathrm{O}$ is present in the flame generated soot samples $(0.5 \%)$, but MILAGRO (h) does not contain this functional group. The $\mathrm{C} / \mathrm{O}$ ratios of MILAGRO $(\mathrm{h})$ and the flame generated soot are also very similar (see Table 1). However, MILAGRO (h) is more graphitic than the flame generated soot, as demonstrated by its $\% \mathrm{sp}^{2}$ value that is $\sim 13 \%$ higher. NIST $(\mathrm{k})$ and $(\mathrm{l})$ both contain a higher percentage of carboxyl than alcohol/O-alkyl-C, which is a characteristic of diesel soot. However, the compositional breakdowns show that these atmospheric samples are significantly more oxygenated than diesel soot and display $\mathrm{C} / \mathrm{O}$ ratios similar to 
the flame generated soot. NIST (1) displays greater structural ordering than both diesel soot and the flame generated soot, as demonstrated by a $\mathrm{sp}^{2}$ value of $71 \%$.

The compositional breakdown of MILAGRO (g) is different to all of the BC SRMs. A lower amount of aromatic-C and a higher presence of oxygen containing functional groups are observed. Although this sample has a $\mathrm{C} / \mathrm{O}$ ratio similar to the flame generated soot, it is only $40 \% \mathrm{sp}^{2}$ hybridized and therefore more structurally disordered than the majority of BC SRMs. NIST (j) displays an even lower percentage of aromatic-C than MILAGRO (g). This sample is highly oxygenated, displaying a $\mathrm{C} / \mathrm{O}$ ratio of $35 / 65$ and contains a higher proportion of phenolic- $\mathrm{C} /$ ketone $\mathrm{C}=\mathrm{O}$ compared to the $\mathrm{BC}$ SRMs. NIST (j) is structurally disordered with a $\mathrm{sp}^{2}$ value of only $29 \%$.

In summary, there is a considerable amount of variation in the degree of oxidation, relative amounts of functional groups present and $\% \mathrm{sp}^{2}$ hybridization values for the anthropogenic combustion particles. Some atmospheric particles display compositional breakdowns similar to those of BC SRMs, while others appear more oxygenated. This may be due to atmospheric aging or contributions from combustion sources that are not as well represented by the BC SRMs studied. Another similarity with the BC SRMs is the presence benzoquinone.

The compositional breakdowns of biomass burn particles are illustrated in Figure 8(c). Some of these samples were collected at source and therefore definitely originated from biomass burns (Flagstaff, Yosemite). However, other samples (ACE Asia (c) and (d) and MILAGRO (e) and (f)) are ambient samples. They are placed in this category based on meteorology information, which suggests some influence from biomass burn sources. A comparison of Figures 8(a) and (c) suggest that the BC SRMs and biomass burn particles contain similar functional groups, but in different proportions. The biomass burn particles are highly oxygenated and contain functional groups that are not observed in the BC SRMs, such as carbonyl-C. The derived $\mathrm{C} / \mathrm{O}$ ratios presented in Table 1 confirm the difference in oxygenation between the biomass burn particles and BC SRMs.

The dominant functional group for most biomass burn particles is alcohol/O-alkyl-C, rather than aromatic-C as observed for the BC SRMs. The biomass burn particles studied contain higher amounts of phenolic-C/ketone $\mathrm{C}=\mathrm{O}$ compared with the $\mathrm{BC}$ SRMs and anthropogenic combustion particles. This observation is reasonable, as a variety of phenolic compounds, including guaiacols, catechols and syringols, are known to form during the combustion of biomass, mainly from lignin pyrolysis [Fine, et 
al., 2001; Rogge, et al., 1998]. The \% $\mathrm{sp}^{2}$ hybridization values for the biomass burn particles are generally much lower than for the BC SRMs. This demonstrates that biomass burn particles do not display a high degree of structural ordering, unlike some anthropogenic combustion particles.

The particles that definitely originate from biomass burn sources contain no benzoquinone. Backward trajectory calculations show that ACE Asia (c) and (d) were influenced by mixed combustion sources [Maria, et al., 2004]. The influence of both anthropogenic and biomass burn combustion is evident in the compositional breakdown of these samples. Anthropogenic combustion is evident from a high percentage of aromatic-C compared to pure biomass burn particles, in addition to the presence of benzoquinone. Biomass burn influence is evident from the high proportion of oxygen containing functional groups present. The MILAGRO (f) spectrum also shows the presence of benzoquinone, which may suggest that this sample was subject to influences from both combustion and biomass burn sources.

Tar balls collected in Yosemite National Park, CA, exhibit a considerably different compositional breakdown compared to particles generated during a biomass burn in Flagstaff, AZ, despite their similar $\mathrm{C} / \mathrm{O}$ ratio and $\mathrm{sp}^{2}$ hybridization values (Yosemite - 55/45 (9\%), Flagstaff - 53/47 $(5 \%))$. Variation in the relative proportion and type of functional groups present in both samples is observed. The functional group $\mathrm{C}=\mathrm{O} / \mathrm{CH}_{3}, \mathrm{CH}_{2}, \mathrm{CH}$ is present exclusively in tar balls, whereas carbonyl-C and aliphatic-C are observed in the particles collected in Flagstaff, AZ.

Figure 8(d) presents the compositional breakdowns for the three HULIS studied. Much like the biomass burn particles, oxygenated functional groups dominate the spectral breakdown as supported by $\mathrm{C} / \mathrm{O}$ ratios of 63/37, 54/46 and 58/42 for Suwannee River aquatic NOM 1R101N, Suwannee River fulvic acid and humic acid, respectively. These $\mathrm{C} / \mathrm{O}$ ratios are in good agreement with elemental compositions measured independently [International Humic Substances Society]. The fulvic and humic acids exhibit very similar compositional breakdowns to one another, with the carboxyl functional group dominating. Phenolic- $\mathrm{C} /$ ketone $\mathrm{C}=\mathrm{O}$ is present in higher proportions than observed in the pure biomass burning particles (Yosemite and Flagstaff) and a greater amount of aromatic-C is present. The same functional groups are present all three HULIS samples, but the relative proportion of these differs. Alcohol/O-alkyl-C is the dominant functional group in the Suwannee River aquatic NOM sample, while carboxyl is most prevalent in the Suwannee River fulvic and humic acid samples. Aromatic-C is present in much lower quantities in the Suwannee River aquatic NOM, which is consistent with the pure 
biomass burn samples. Suwannee River aquatic NOM also has a $\mathrm{sp}^{2}$ hybridization value of $7 \%$, which is more comparable with the biomass burn samples. This value is considerably lower than for the Suwannee River humic and fulvic acids, 28 and 29\%, respectively. Benzoquinone is not present in the three HULIS samples studied.

Overall, the biomass burn particles studied are better represented by HULIS than BC SRMs. This is determined by greater similarities in $\mathrm{C} / \mathrm{O}$ ratios, $\% \mathrm{sp}^{2}$ hybridization values and higher amounts of oxygenated functional groups and lower amounts of aromatic-C. However, the relative proportions of the functional groups present in the HULIS and biomass burn particles studied differs. Humic and fulvic acids are not a single chemical species, but rather a very complex mix of natural material, which exhibit an extremely wide range of physical and chemical properties. Therefore, it is no surprise that these do not provide an exact match to atmospheric biomass burn aerosol, which itself is variable. HULIS is effectively part of the starting material, which then undergoes combustion to produce biomass burn aerosol. Therefore, it should be expected that chemical evolution during the combustion process will result in differences in the relative amounts of functional groups present in both species.

\section{Concluding Remarks}

We demonstrate that STXM coupled with NEXAFS spectroscopy provides a unique method for performing detailed studies of local chemical bonding, $\mathrm{C} / \mathrm{O}$ ratios and structural ordering of single atmospheric particles, BC and HULIS SRMs. Comparison of NEXAFS spectral signatures enables assessment of the suitability of SRMs for representing the diverse range of atmospheric particles sampled. This diversity is present for particles sampled during different field campaigns and at one location over a short time period. This may be due to the influence of different sources as well as the complicated and undefined process of atmospheric aging. As a result, no one standard provides a unique representation of a certain class of atmospheric particles. However, it is possible to categorize atmospheric particles by the dominant functional groups present, the degree of $\mathrm{sp}^{2}$ hybridization and their $\mathrm{C} / \mathrm{O}$ ratios. Using these criteria, it may be possible to differentiate between $\mathrm{BC}$ and biomass burn atmospheric particles.

$\mathrm{BC}$ atmospheric particles are characterized by a high proportion of the aromatic-C functional group, the presence of benzoquinone, high $\% \mathrm{sp}^{2}$ hybridization (indicating some structural ordering) and higher $\mathrm{C} / \mathrm{O}$ ratios than for biomass burn particles. In contrast, biomass burn particles have lower 
amounts of aromatic-C, low \% $\mathrm{sp}^{2}$ hybridization and high oxygenation relative to $\mathrm{BC}$ particles. More specifically, we deduce that a high proportion of the $\mathrm{BC}$ atmospheric particles display characteristic features similar to flame generated soot, while others appear similar to resistively heated graphite and diesel soot. The biomass burn particles studied here display compositions and structural ordering dissimilar to the BC SRMs studied and are better represented by HULIS. Figure 9 illustrates these conclusions by plotting the mean percentage contribution of each functional group to the total carbon in the sample. Quinone-C, aromatic-C and the sum of all oxygen containing functional groups are presented for the four classes of materials. As there is some ambiguity about the assignment of the aliphatic-C/aromatic carbonyl functional group at $287.4 \mathrm{eV}$, this transition is assumed to contribute fully to the sum of the oxygen containing functional groups in Figure 9; therefore the data presents an upper limit.

This combined data supports the recommendation by the ISCBCRM of $n$-hexane soot as a SRM for atmospheric BC. However, HULIS may provide a better representation of some biomass burn particles. Knowledge of other structural and chemical properties in addition to those studied here (light scattering and absorption properties, surface functionality, and porosity to name a few), are important for the recommendation of a SRM to represent atmospheric aerosol. Recent work by Kirchstetter and Novakov suggests the use of soot produced in an inverted methane/air diffusion flame for evaluating BC light absorption measurement methods. This soot is uniquely composed of BC, with a reported single scattering albedo of 0.15 and a mass absorption efficiency of $8.5 \mathrm{~m}^{2} \mathrm{~g}^{-1}$ [Kirchstetter and Novakov, submitted]. This soot was studied here is representative of some atmospheric BC, thus it may be a useful BC SRM.

\section{Acknowledgements}

This work was supported by the U.S. Department of Energy's Atmospheric Science Program (Office of Science, BER) and the Division of Chemical Science, Geoscience, Bioscience, Materials Science and the Office of Basic Energy Sciences, of the U.S. Department of Energy at the Advanced Light Source and Lawrence Berkeley National Laboratory under contract number DE-AC03-76S00098. ALS beamline scientists T. Tyliszczak and A. L. D. Kilcoyne are thanked for support at beamlines 11.0.2 and 5.3.2, respectively. M. Gershenzon, J. L. Hand, T. W. Kirchstetter, A. Laskin, H. A. Michelson, K. A. Prather, M. S. Robinson, L. M. Russell and D. M. Smith are gratefully acknowledged for supplying samples. A. Braun and C. Lenardi are thanked for the use of NEXAFS spectra they recorded. B. D. M acknowledges support from the Laboratory Science Teacher Professional 
Development Program, Office of Science, U.S. Department of Energy. L. M. Russell acknowledges support for collection of ACE-Asia samples, which was provided by NSF grant ATM-0002035.

\section{References}

Akhter, M. S., Chughtai, A. R. \& Smith, D. M. (1985), The structure of hexane soot I: Spectroscopic studies, Applied Spectroscopy, 39, 143-153.

Andreae, M. O. \& Gelencser, A. (2006), Black carbon or brown carbon? The nature of light-absorbing carbonaceous aerosols, Atmospheric Chemistry and Physics, 6, 3131-3148.

Berger, S. D., McKenzie, D. R. \& Martin, P. J. (1988), EELS analysis of vacuum arc-deposited diamond-like films, Philosophical Magazine Letters, 57, 285-290.

Bond, T. C. \& Bergstrom, R. W. (2006), Light absorption by carbonaceous particles: An investigative review, Aerosol Science and Technology, 40, 27-67.

Braun, A., Shah, N., Huggins, F. E., Huffman, G. P., Wirick, S., Jacobsen, C., Kelly, K. \& Sarofim, A. F. (2004), A study of diesel PM with X-ray microspectroscopy, Fuel, 83, 997-1000.

Chughtai, A. R., Brooks, M. E. \& Smith, D. M. (1996), Hydration of black carbon, Journal of Geophysical Research-Atmospheres, 101, 19505-19514.

Chughtai, A. R., Kim, J. M. \& Smith, D. M. (2002), The effect of air/fuel ratio on properties and reactivity of combustion soots, Journal of Atmospheric Chemistry, 43, 21-43.

Chughtai, A. R., Miller, N. J., Smith, D. M. \& Pitts, J. R. (1999a), Carbonaceous particle hydration III, Journal of Atmospheric Chemistry, 34, 259-279.

Chughtai, A. R., Williams, G. R., Atteya, M. M. O., Miller, N. J. \& Smith, D. M. (1999b), Carbonaceous particle hydration, Atmospheric Environment, 33, 2679-2687.

Chung, S. H. \& Seinfeld, J. H. (2005), Climate response of direct radiative forcing of anthropogenic black carbon, Journal of Geophysical Research-Atmospheres, 110, doi:10.1029/2004JD005441.

Cody, G. D., Ade, H., Wirick, S., Mitchell, G. D. \& Davis, A. (1998), Determination of chemicalstructural changes in vitrinite accompanying luminescence alteration using C-NEXAFS analysis, Organic Geochemistry, 28, 441-455.

Cody, G. D., Botto, R. E., Ade, H., Behal, S., Disko, M. \& Wirick, S. (1995), Inner-shell spectroscopy and imaging of a subbituminous coal: in-situ analysis of organic and inorganic microstructure using C(1s)-NEXAFS, Ca(2p)-NEXAFS, and C1(2s)-NEXAFS, Energy \& Fuels, 9, 525-533.

Coffman, F. L., Cao, R., Pianetta, P. A., Kapoor, S., Kelly, M. \& Terminello, L. J. (1996), Near-edge Xray absorption of carbon materials for determining bond hybridization in mixed $\mathrm{sp}^{2} / \mathrm{sp}^{3}$ bonded materials, Applied Physics Letters, 69, 568-570. 
Currie, L. A., Benner, B. A., Kessler, J. D., Klinedinst, D. B., Klouda, G. A., Marolf, J. V., Slater, J. F., Wise, S. A., Cachier, H., Cary, R., Chow, J. C., Watson, J., Druffel, E. R. M., Masiello, C. A., Eglinton, T. I., Pearson, A., Reddy, C. M., Gustafsson, O., Quinn, J. G., Hartmann, P. C., Hedges, J. I., Prentice, K. M., Kirchstetter, T. W., Novakov, T., Puxbaum, H. \& Schmid, H. (2002), A critical evaluation of interlaboratory data on total, elemental, and isotopic carbon in the carbonaceous particle reference material, NIST SRM 1649a, Journal of Research of the National Institute of Standards and Technology, 107, 279-298.

di Stasio, S. \& Braun, A. (2006), Comparative NEXAFS study on soot obtained from an ethylene/air flame, a diesel engine, and graphite, Energy \& Fuels, 20, 187-194.

Fine, P. M., Cass, G. R. \& Simoneit, B. R. T. (2001), Chemical characterization of fine particle emissions from fireplace combustion of woods grown in the northeastern United States, Environmental Science \& Technology, 35, 2665-2675.

Goldberg, E. D. (1985), Black carbon in the environment, Wiley, New York.

Hand, J. L., Malm, W. C., Laskin, A., Day, D., Lee, T., Wang, C., Carrico, C., Carrillo, J., Cowin, J. P., Collett, J. \& Iedema, M. J. (2005), Optical, physical, and chemical properties of tar balls observed during the Yosemite Aerosol Characterization Study, Journal of Geophysical Research-Atmospheres, 110, doi:10.1029/2004JD005728.

Havers, N., Burba, P., Lambert, J. \& Klockow, D. (1998), Spectroscopic characterization of humic-like substances in airborne particulate matter, Journal of Atmospheric Chemistry, 29, 45-54.

Henke, B. L., Lee, P., Tanaka, T. J., Shimabukuro, R. L. \& Fuikawa, B. K. (1982), Low-energy X-ray interaction coefficients: Photoabsorption, scattering, and reflection : $\mathrm{E}=100-2000 \mathrm{eV} \mathrm{Z}=1-94$, Atomic Data and Nuclear Data Tables, 27, 1-144.

Hitchcock, A. P., Koprinarov, I., Tylisczcak, T., Rightor, E. G., Mitchell, G. E., Dineen, M. T., Hayes, F., Lidy, W., Priester, R. D., Urquhart, S. G., Smith, A. P. \& Ade, H. (2001), Optimization of scanning transmission X-ray microscopy for the identification and quantitation of reinforcing particles in polyurethanes, Ultramicroscopy, 88, 33-49.

Hoffer, A., Gelencser, A., Guyon, P., Kiss, G., Schmid, O., Frank, G. P., Artaxo, P. \& Andreae, M. O. (2006), Optical properties of humic-like substances (HULIS) in biomass-burning aerosols, Atmospheric Chemistry and Physics, 6, 3563-3570.

Huggins, F. E., Huffman, G. P. \& Robertson, J. D. (2000), Speciation of elements in NIST particulate matter SRMs 1648 and 1650, Journal of Hazardous Materials, 74, 1-23.

International Humic Substances Society http://www.ihss.gatech.edu/.

Jacobson, M. Z. (2001), Strong radiative heating due to the mixing state of black carbon in atmospheric aerosols, Nature, 409, 695-697.

Jacobson, M. Z. (2004), Climate response of fossil fuel and biofuel soot, accounting for soot's feedback to snow and sea ice albedo and emissivity, Journal of Geophysical Research-Atmospheres, 109, doi:10.1029/2004JD004945. 
Jones, G. S., Jones, A., Roberts, D. L., Stott, P. A. \& Williams, K. D. (2005), Sensitivity of global-scale climate change attribution results to inclusion of fossil fuel black carbon aerosol, Geophysical Research Letters, 32, doi:10.1029/2005GL023370.

Kirchstetter, T. W. \& Novakov, T. (submitted), Controlled generation of black carbon particles from a diffusion flame and applications in evaluating BC measurement methods, Atmos. Environ.

Kiss, G., Varga, B., Gelencser, A., Krivacsy, Z., Molnar, A., Alsberg, T., Persson, L., Hansson, H. C. \& Facchini, M. C. (2001), Characterisation of polar organic compounds in fog water, Atmospheric Environment, 35, 2193-2200.

Krivacsy, Z., Gelencser, A., Kiss, G., Meszaros, E., Molnar, A., Hoffer, A., Meszaros, T., Sarvari, Z., Temesi, D., Varga, B., Baltensperger, U., Nyeki, S. \& Weingartner, E. (2001), Study on the chemical character of water soluble organic compounds in fine atmospheric aerosol at the Jungfraujoch, Journal of Atmospheric Chemistry, 39, 235-259.

Krivacsy, Z., Kiss, G., Varga, B., Galambos, I., Sarvari, Z., Gelencser, A., Molnar, A., Fuzzi, S., Facchini, M. C., Zappoli, S., Andracchio, A., Alsberg, T., Hansson, H. C. \& Persson, L. (2000), Study of humic-like substances in fog and interstitial aerosol by size-exclusion chromatography and capillary electrophoresis, Atmospheric Environment, 34, 4273-4281.

Laskin, A., Cowin, J. P. \& Iedema, M. J. (2006), Analysis of individual environmental particles using modern methods of electron microscopy and X-ray microanalysis, Journal of Electron Spectroscopy and Related Phenomena, 150, 260-274.

Laskin, A., Iedema, M. J. \& Cowin, J. P. (2003), Time-resolved aerosol collector for CCSEM/EDX single-particle analysis, Aerosol Science and Technology, 37, 246-260.

Lenardi, C., Marino, M., Barborini, E., Piseri, P. \& Milani, P. (2005), Evaluation of hydrogen chemisorption in nanostructured carbon films by near edge X-ray absorption spectroscopy, European Physical Journal B, 46, 441-447.

Lenardi, C., Piseri, P., Briois, V., Bottani, C. E., Bassi, A. L. \& Milani, P. (1999), Near-edge X-ray absorption fine structure and Raman characterization of amorphous and nanostructured carbon films, Journal of Applied Physics, 85, 7159-7167.

Limbeck, A., Kulmala, M. \& Puxbaum, H. (2003), Secondary organic aerosol formation in the atmosphere via heterogeneous reaction of gaseous isoprene on acidic particles, Geophysical Research Letters, 30, doi:10.1029/2003GL017738.

Ma, Y., Chen, C. T., Meigs, G., Randall, K. \& Sette, F. (1991), High-resolution K-shell photoabsorption measurements of simple molecules, Physical Review A, 44, 1848-1858.

Maria, S. F., Russell, L. M., Gilles, M. K. \& Myneni, S. C. B. (2004), Organic aerosol growth mechanisms and their climate-forcing implications, Science, 306, 1921-1924.

Masiello, C. \& Schmidt, M. W. I. (1999), International Steering Committee for Black Carbon Reference Materials, (http://www.du.edu/ dwismith/bcsteer.html. 
Mertes, S., Dippel, B. \& Schwarzenbock, A. (2004), Quantification of graphitic carbon in atmospheric aerosol particles by Raman spectroscopy and first application for the determination of mass absorption efficiencies, Journal of Aerosol Science, 35, 347-361.

Michelson, H. A., Tivanski, A. V., van Poppel, L., Dansson, M. A., Gilles, M. K. \& Buseck, P. (2007), New particle formation from pulsed laser irradiation of soot aggregates studied with SMPS, TEM, NEXAFS and modeling, Applied Optics, 46, 959-977.

Mukai, H. \& Ambe, Y. (1986), Characterization of a humic-like brown substance in airborne particulate matter and tentative identification of its origin, Atmospheric Environment, 20, 813-819.

Myneni, S. C. B. (2002), Soft X-ray spectroscopy and spectromicroscopy studies of organic molecules in the environment, in Applications of Synchrotron Radiation in Low-Temperature Geochemistry and Environmental Sciences, edited, pp. 485-579, Mineralogical Soc America, Washington.

Posfai, M., Gelencser, A., Simonics, R., Arato, K., Li, J., Hobbs, P. V. \& Buseck, P. R. (2004), Atmospheric tar balls: Particles from biomass and biofuel burning, Journal of Geophysical ResearchAtmospheres, 109, doi:10.1029/2003JD004169.

Richter, H. \& Howard, J. B. (2000), Formation of polycyclic aromatic hydrocarbons and their growth to soot - a review of chemical reaction pathways, Progress in Energy and Combustion Science, 26, 565608 .

Rogaski, C. A., Golden, D. M. \& Williams, L. R. (1997), Reactive uptake and hydration experiments on amorphous carbon treated with $\mathrm{NO}_{2}, \mathrm{SO}_{2}, \mathrm{O}_{3}, \mathrm{HNO}_{3}$, and $\mathrm{H}_{2} \mathrm{SO}_{4}$, Geophysical Research Letters, 24 , 381-384.

Rogge, W. F., Hildemann, L. M., Mazurek, M. A., Cass, G. R. \& Simoneit, B. R. T. (1998), Sources of fine organic aerosol. 9. Pine, oak and synthetic log combustion in residential fireplaces, Environmental Science \& Technology, 32, 13-22.

Rosen, H. \& Novakov, T. (1977), Raman scattering and characterization of atmospheric aerosol particles, Nature, 266, 708-710.

Russell, L. M., Maria, S. F. \& Myneni, S. C. B. (2002), Mapping organic coatings on atmospheric particles, Geophysical Research Letters, 29, doi:10.1029/2002GL014874.

Sasaki, J., Aschmann, S. M., Kwok, E. S. C., Atkinson, R. \& Arey, J. (1997), Products of the gas-phase $\mathrm{OH}$ and $\mathrm{NO}_{3}$ radical-initiated reactions of naphthalene, Environmental Science \& Technology, 31, 31733179.

Scheinost, A. C., Kretzschmar, R., Christl, I. \& Jacobsen, C. (2001), Humic substances: structures, models and functions, Royal Society of Chemistry, Cambridge.

Stöhr, J. (2003), NEXAFS Spectroscopy, First ed., Springer-Verlag, Berlin Heidelberg. 
Su, D. S., Muller, J. O., Jentoft, R. E., Rothe, D., Jacob, E. \& Schlogl, R. (2004), Fullerene-like soot from EuroIV diesel engine: consequences for catalytic automotive pollution control, Topics in Catalysis, 30-31, 241-245.

Sze, S. K., Siddique, N., Sloan, J. J. \& Escribano, R. (2001), Raman spectroscopic characterization of carbonaceous aerosols, Atmospheric Environment, 35, 561-568.

Tivanski, A. V., Hopkins, R. J. \& Gilles, M. K. (submitted), Oxygenated interface on biomass burn tar balls determined by single particle scanning transmission X-ray microscopy, Journal of Physical Chemistry A.

Urquhart, S. G. \& Ade, H. (2002), Trends in the carbonyl core (C 1s, O 1s) -> pi*c=o transition in the near-edge X-ray absorption fine structure spectra of organic molecules, Journal of Physical Chemistry $B, 106,8531-8538$.

Urquhart, S. G., Ade, H., Rafailovich, M., Sokolov, J. S. \& Zhang, Y. (2000), Chemical and vibronic effects in the high-resolution near-edge X-ray absorption fine structure spectra of polystyrene isotopomers, Chemical Physics Letters, 322, 412-418.

Urquhart, S. G., Smith, A. P., Ade, H. W., Hitchcock, A. P., Rightor, E. G. \& Lidy, W. (1999), Nearedge X-ray absorption fine structure spectroscopy of MDI and TDI polyurethane polymers, Journal of Physical Chemistry B, 103, 4603-4610.

Warwick, T., Ade, H., Kilcoyne, D., Kritscher, M., Tylisczcak, T., Fakra, S., Hitchcock, A., Hitchcock, P. \& Padmore, H. (2002), A new bend-magnet beamline for scanning transmission X-ray microscopy at the Advanced Light Source, Journal of Synchrotron Radiation, 9, 254-257.

Wentzel, M., Gorzawski, H., Naumann, K. H., Saathoff, H. \& Weinbruch, S. (2003), Transmission electron microscopical and aerosol dynamical characterization of soot aerosols, Journal of Aerosol Science, 34, 1347-1370.

Wyslouzil, B. E., Carleton, K. L., Sonnenfroh, D. M., Rawlins, W. T. \& Arnold, S. (1994), Observation of hydration of single, modified carbon aerosols, Geophysical Research Letters, 21, 2107-2110.

Zappoli, S., Andracchio, A., Fuzzi, S., Facchini, M. C., Gelencser, A., Kiss, G., Krivacsy, Z., Molnar, A., Meszaros, E., Hansson, H. C., Rosman, K. \& Zebuhr, Y. (1999), Inorganic, organic and macromolecular components of fine aerosol in different areas of Europe in relation to their water solubility, Atmospheric Environment, 33, 2733-2743. 
Table 1

\begin{tabular}{|c||c||c||c|}
\hline Category & Sample & \% sp & C/O \\
\hline \hline BC SRMs & HOPG & 100 & $100 / 0$ \\
& RHG & 69 & $96 / 4$ \\
& MG & 66 & \\
& n-Hexane soot & 66 & $87 / 13$ \\
& Ethylene soot & 63 & $84 / 16$ \\
& Methane soot & 60 & $84 / 16$ \\
& Diesel exhaust soot & 56 & \\
& Palas soot & 52 & \\
& Amorphous carbon & 41 & \\
\hline BC Aerosol & MILAGRO (i) & 82 & $99 / 1$ \\
& MILAGRO (h) & 76 & $84 / 16$ \\
& NIST (1) & 71 & $85 / 15$ \\
& NIST (k) & 45 & $76 / 24$ \\
& MILAGRO (g) & 40 & $82 / 18$ \\
& NIST (j) & 29 & $35 / 65$ \\
\hline \multirow{2}{*}{ From Suwannee River } & Fulvic acid 1S101F & 29 & $54 / 46$ \\
& Humic acid 2S101H & 28 & $58 / 42$ \\
& Aquatic NOM 1R101N & 7 & $63 / 37$ \\
\hline Biomass Burn Aerosol & ACE-Asia (c) & 41 & \\
& ACE-Asia (d) & 34 & \\
& MILAGRO (f) & 10 & $65 / 35$ \\
& Yosemite 'tar balls' & 9 & $55 / 45$ \\
& MILAGRO (e) & 6 & $67 / 32$ \\
& Flagstaff & 5 & $53 / 47$ \\
\hline
\end{tabular}

Table $1-\% \mathrm{sp}^{2}$ hybridization values and selected $\mathrm{C} / \mathrm{O}$ ratios for $\mathrm{BC}$ reference materials, HULIS and atmospheric samples studied. Where no value is presented in the $\mathrm{C} / \mathrm{O}$ column, no $\mathrm{O}$ K-edge NEXAFS spectrum was recorded. 


\section{Figure 1}

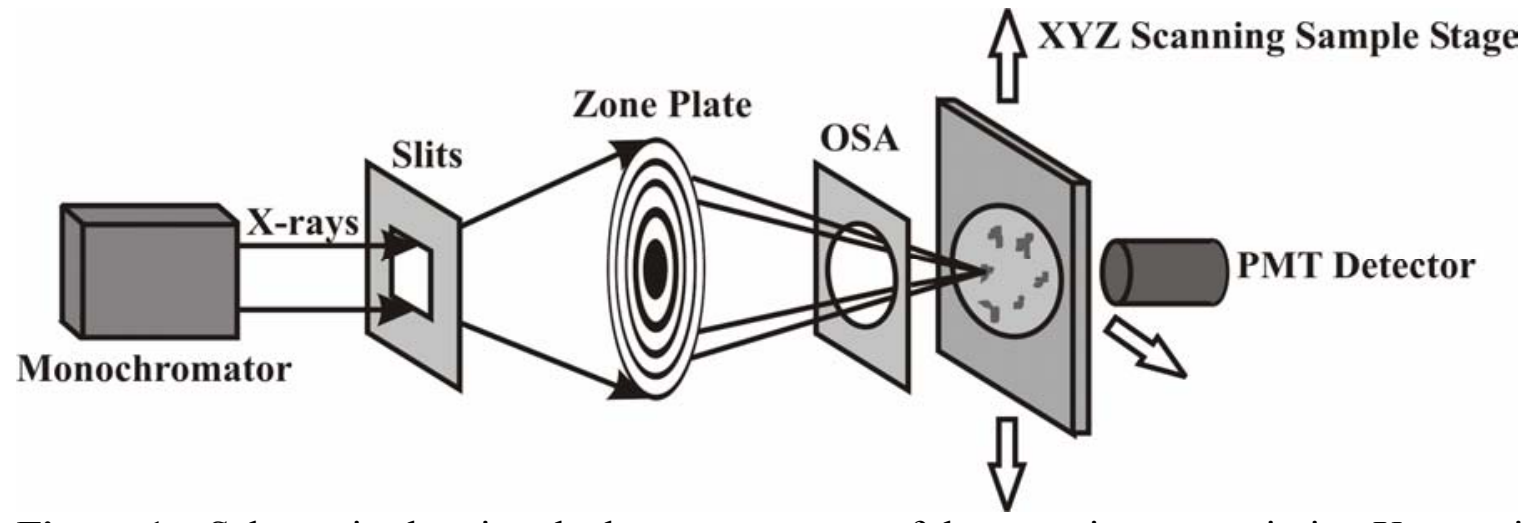

Figure 1 - Schematic showing the key components of the scanning transmission X-ray microscope at beamlines 5.3.2 and 11.0.2 of the Advanced Light Source, Berkeley.

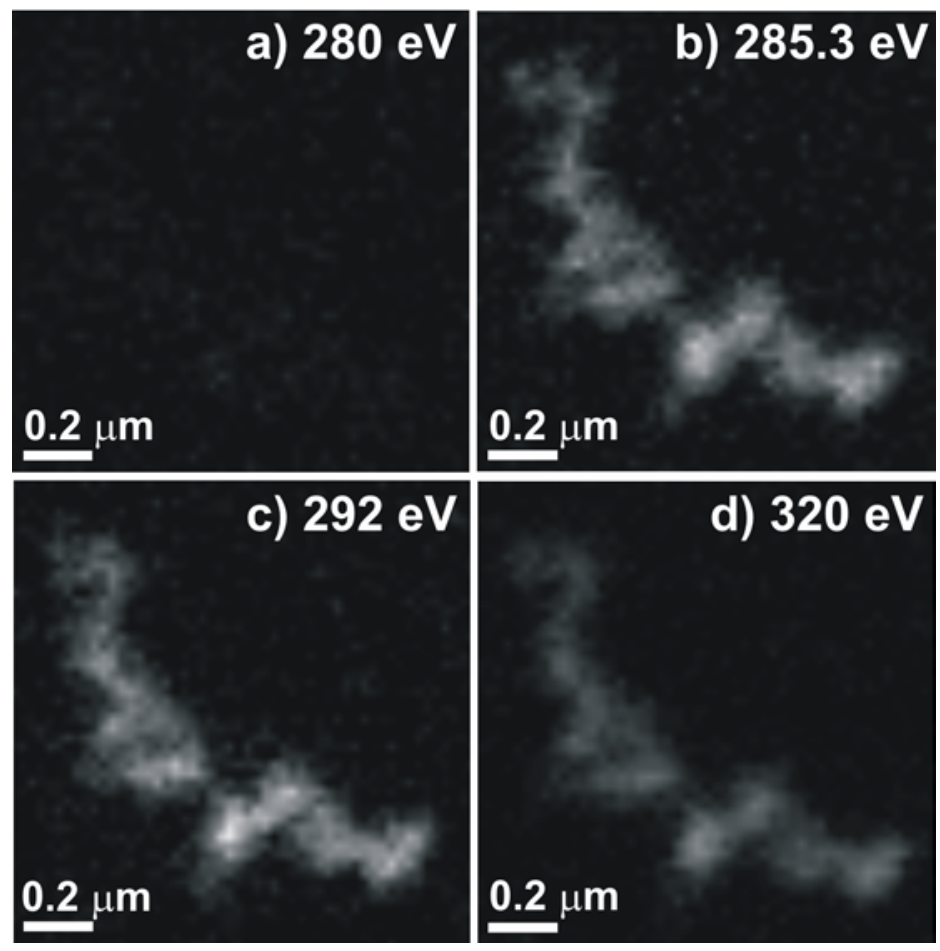

Figure 2 - STXM images, presented on the same optical density scale, of a black carbon particle collected during the MILAGRO field campaign (a) pre-edge, $280 \mathrm{eV}$, (b) $1 \mathrm{~s}-\pi^{*}$ aromatic $\mathrm{C}=\mathrm{C}, 285.3$ $\mathrm{eV}$, (c) $1 \mathrm{~s}-\sigma^{*}$ aromatic $\mathrm{C}=\mathrm{C}, 292 \mathrm{eV}$ and (d) post-edge, $320 \mathrm{eV}$. The higher image contrast at 285.3 and $292 \mathrm{eV}$ relative to the pre-edge shows the presence of aromatic $\mathrm{C}=\mathrm{C}$. 


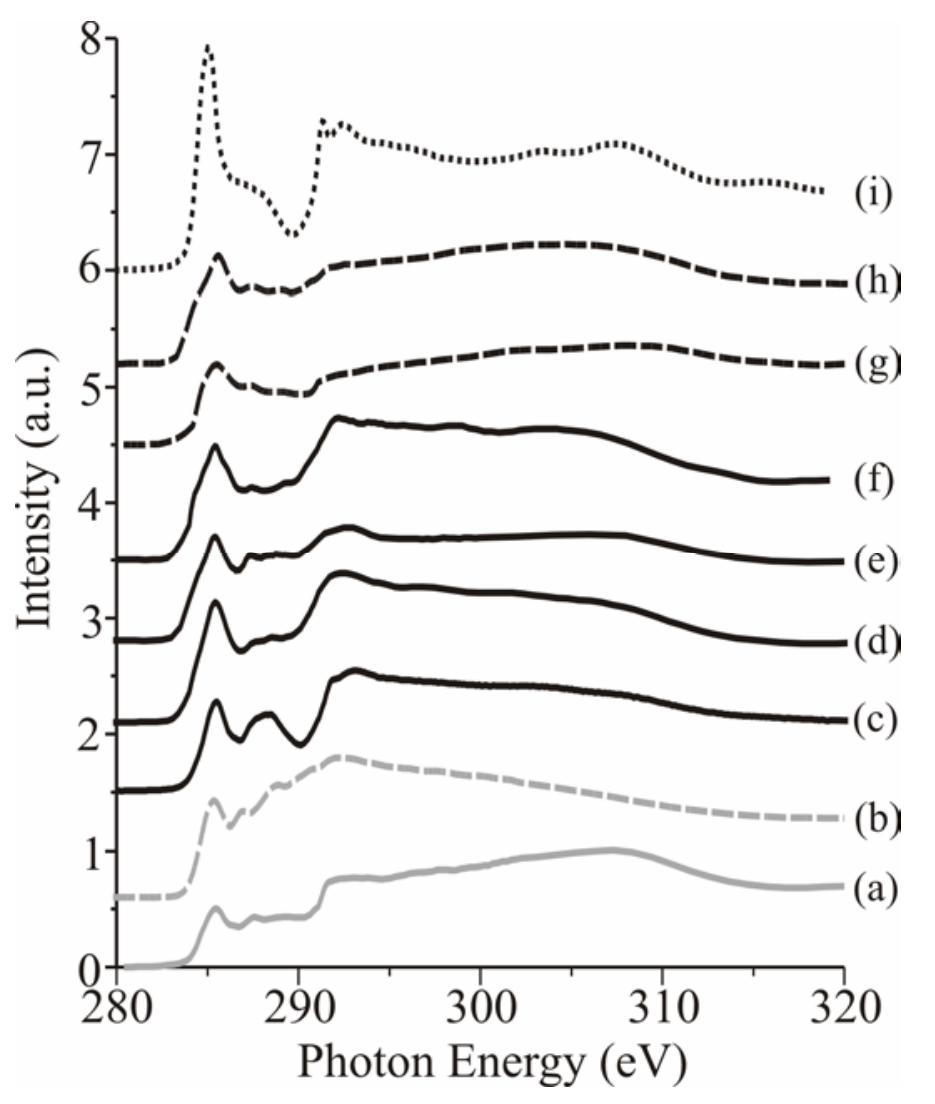

Figure 3 - Carbon K-edge NEXAFS spectra of surrogate soot samples (a) amorphous carbon, (b) Palas soot, (c) diesel exhaust soot [di Stasio and Braun, 2006], (d) methane soot, (e) ethylene soot, (f) $n$ hexane soot, (g) micronized graphite, (h) resistively heated graphite, (i) highly oriented pyrolytic graphite [Lenardi, et al., 2005]. Spectra with similar contours are categorized using dotted and dashed lines in addition to different grey shades (see text for full details). 


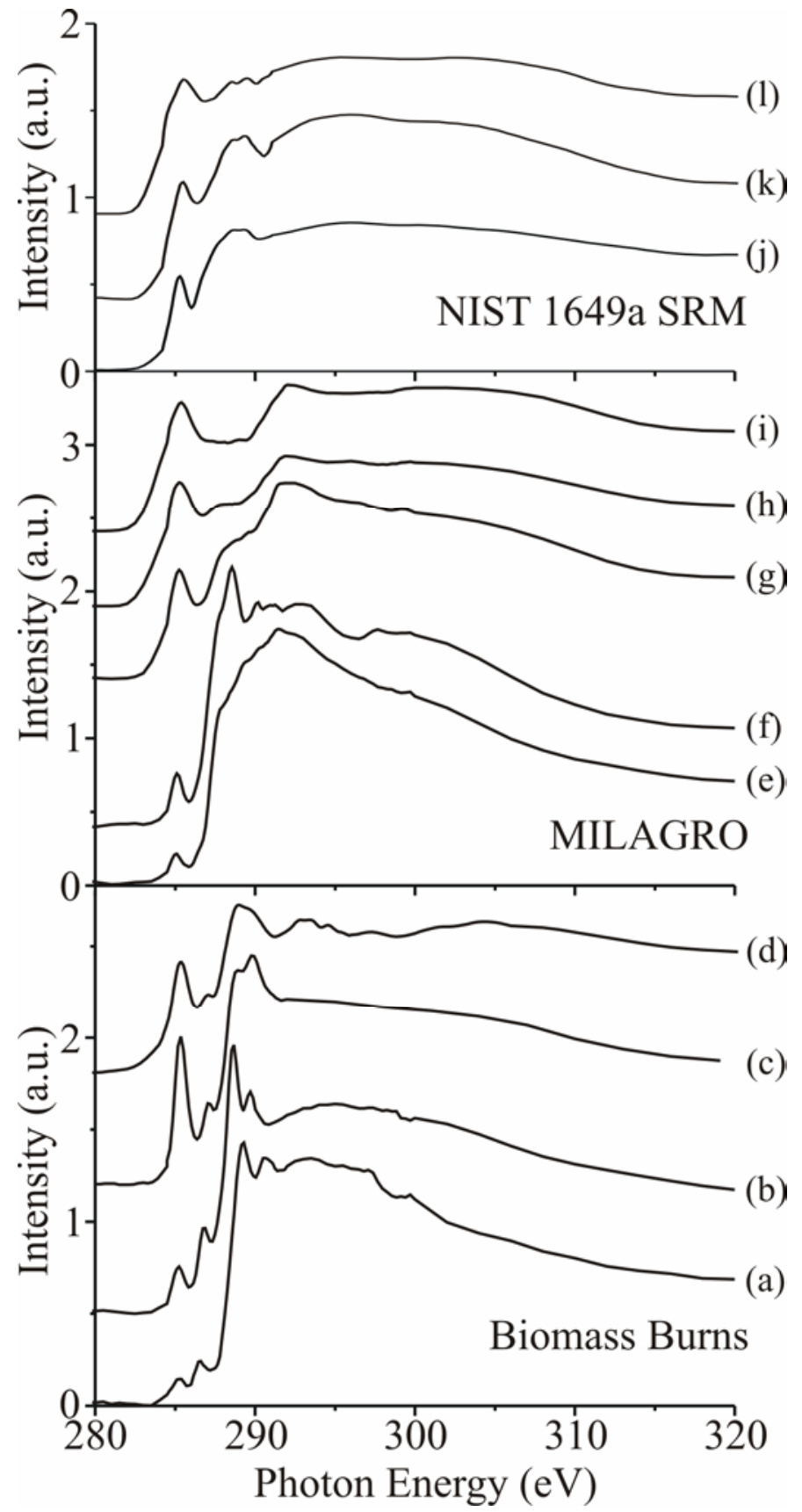

Figure 4 - Carbon K-edge NEXAFS spectra of atmospheric samples (a) Flagstaff, AZ, (b) Yosemite National Park, CA, (c) and (d) ACE Asia, (e), (f), (g), (h), and (i) MILAGRO and (j), (k) and (l) NIST. 


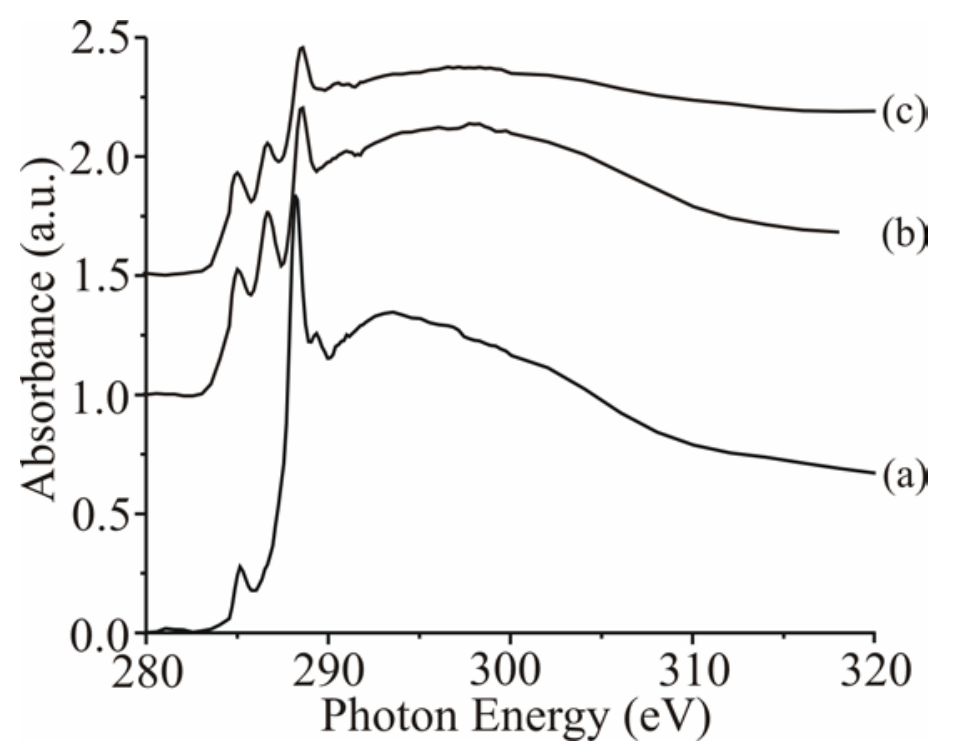

Figure 5 - Carbon K-edge NEXAFS spectra of HULIS standards (a) Suwannee River aquatic NOM 1R101N, (b) Suwannee River humic acid 2S101H and (c) Suwannee River fulvic acid 1S101F.
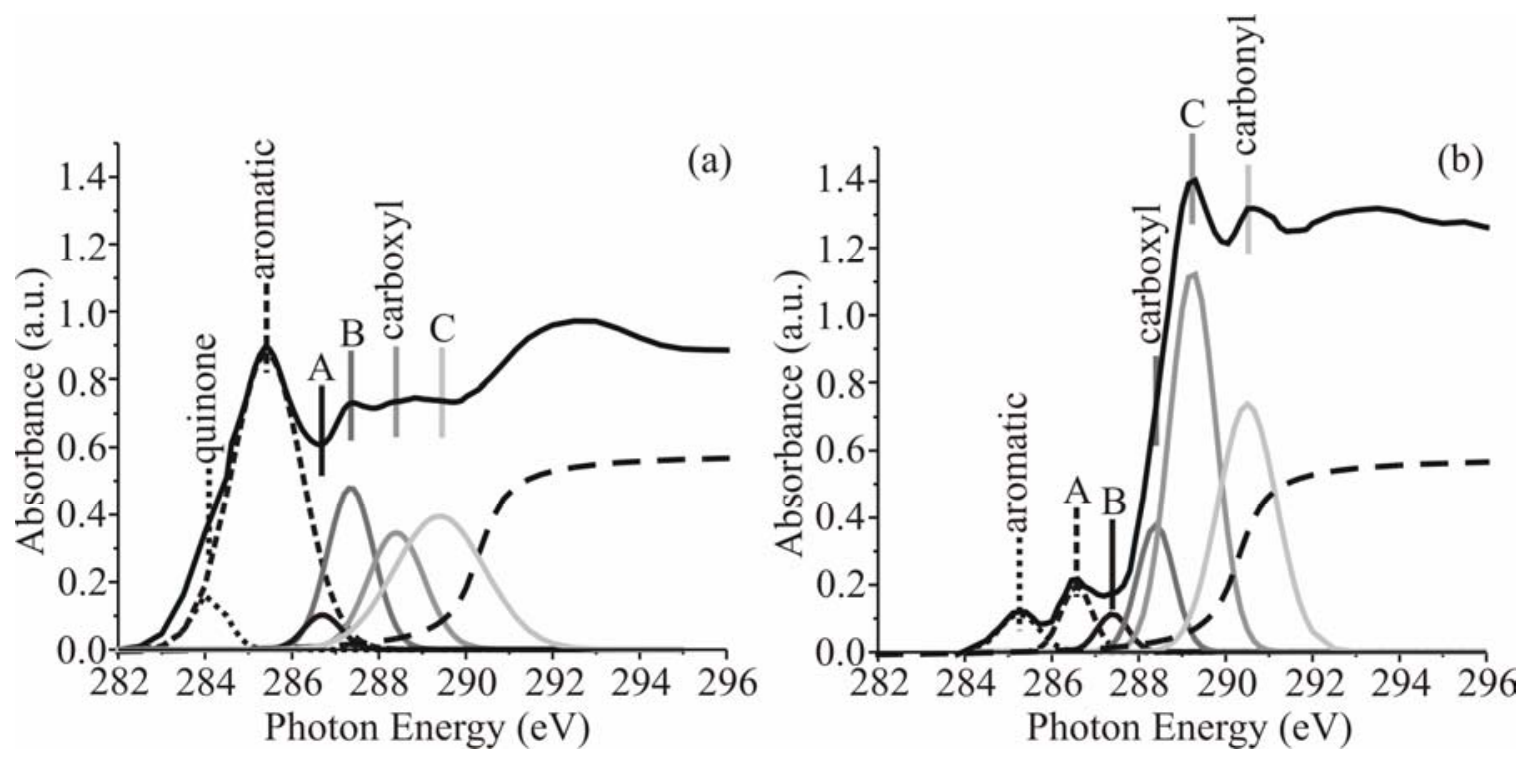

Figure 6 - Carbon K-edge NEXAFS spectra and peak assignments of (a) ethylene soot and (b) a particle collected from Flagstaff, AZ. Different grey shades and line styles indicate specific peak assignments in the spectral fit. 


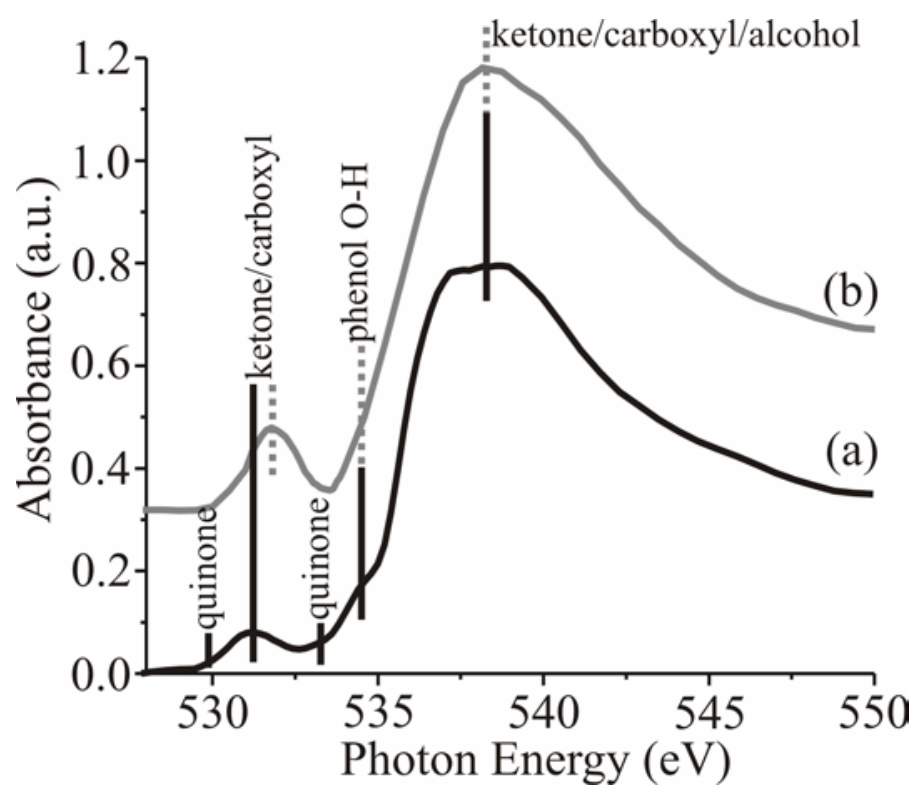

Figure 7 - Oxygen K-edge spectra of (a) ethylene soot and (b) a particle collected from a biomass burn in Flagstaff, AZ. The black lines and dotted grey lines indicate the assignment of resonance transitions occurring in spectra (a) and (b), respectively. 
- quinone $\bullet$ aromatic $\Delta$ phenolic/ketone $\mathrm{C}=\mathrm{O} \quad$ a aliphatic/aromatic carbonyl

- carbonyl $\triangleleft$ carboxyl o alcohol/O-alkyl-C/carbonyl $\times \mathrm{C}=\mathrm{O} / \mathrm{CH}_{3}, \mathrm{CH}_{2}, \mathrm{CH}$
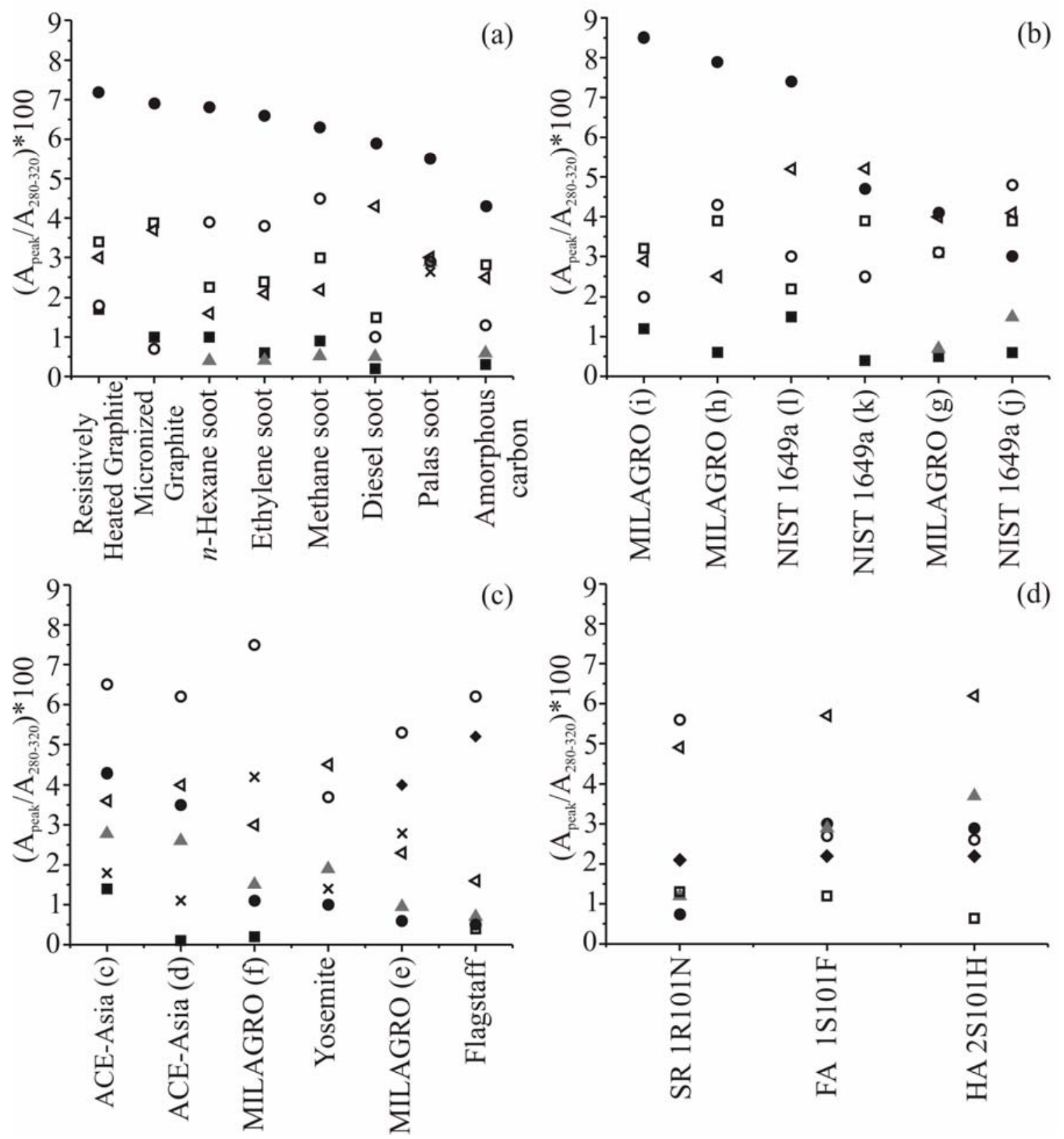

Figure 8 - Compositional breakdown of (a) BC SRMs, (b) anthropogenic combustion atmospheric particles, (c) biomass burn atmospheric particles and (d) HULIS. Composition is presented as the \% contribution of each functional group to the total carbon in the sample, calculated from the integral of the resonances divided by the integral of the $\mathrm{C} \mathrm{K}$-edge spectrum from $280-320 \mathrm{eV}$. Where no symbol is present, a value of $0 \%$ contribution is assumed. 
Figure 9

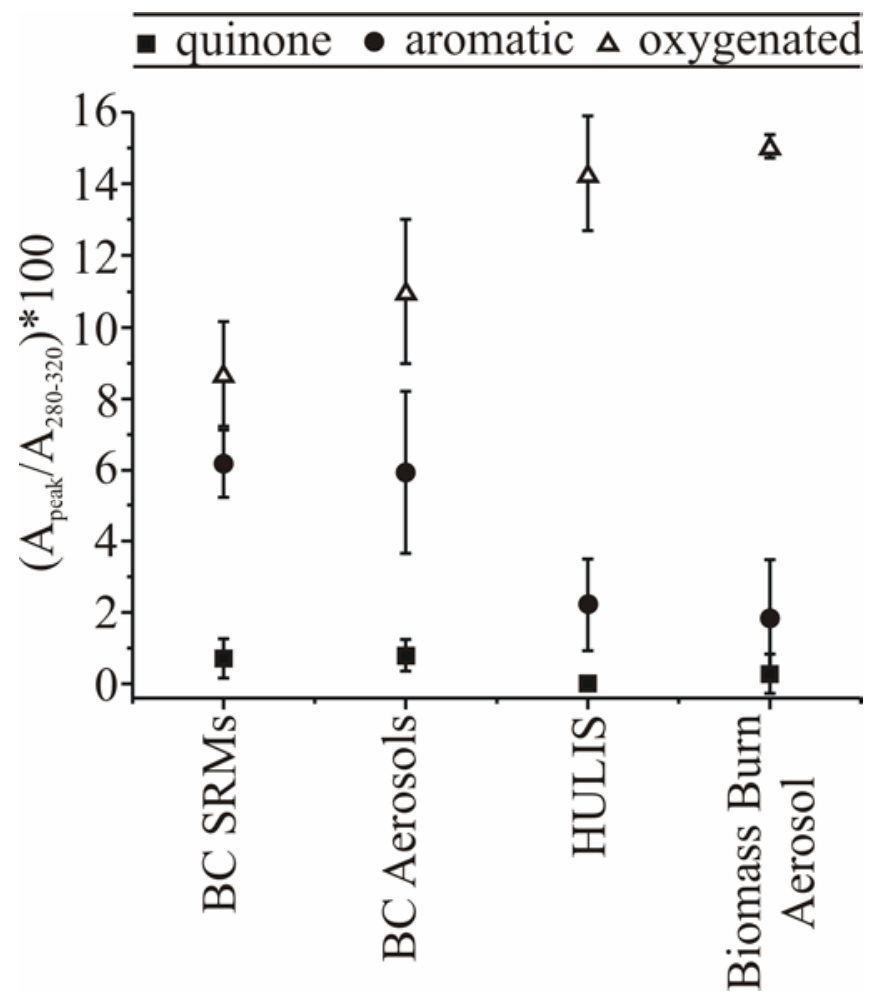

Figure 9 - Summary of the compositional breakdowns shown in Figures 8(a) - (d) for the four classes of materials studied (BC SRMs, BC particles, HULIS and biomass burn particles). The mean percentage that each functional group contributes to the total carbon in the sample is plotted for the four classes of materials for quinone, aromatic and the sum of all oxygen containing functional groups. 